\title{
SOME ASPECTS OF SOLUTION CHROMATOGRAPHY WITH GRADIENTS
}

\author{
Candin liteanu and Simion Gocan \\ Department of Analytical Chemistry, University of Cluj, \\ Cluj, Romania
}

\begin{abstract}
The general problem of using gradients in chromatography is presented. After the classification of the gradients follows a short history of the preparation and use of the devices for various types of gradients. Then the main results are shown insisting on the temperature gradient and describing the use and the theory of the gradient effect in both closed and open columns.
\end{abstract}

\section{INTRODUCTION}

The separation of various substances out of a mixture is one of the major problems of analytical chemistry and chemical technology. For substances with very similar properties the problem is particularly difficult.

Of all the separation methods used at present in technology or analytical chemistry, the chromatographic method is the most effective and, on second thoughts, one can easily realize that there is no other comparable method in point of effectiveness.

As is well known, the chromatographic method is based on the displacement at various rates along a closed or open column of all the mixture constituents. In fact, displacement velocities will vary no matter how similar the chemical properties of the substances in a mixture may be; after a long enough period of time, the distances covered can be noticeably different rendering separation possible.

The displacement of a substance along the column is based essentially on its distribution among the two phases of the column, viz. stationary and mobile. Generally speaking the displacement velocity along the chromatographic column can be plotted as a function

$$
v=\mathrm{f}(\alpha, k)
$$

where $\alpha$ is the two-phase distribution coeflicient of the substance (irrespective of the nature of the process governing the distribution coefficient : dissolution, adsorption, ion exchange) while $k$ is the ratio between the volumes of the two contacting phases $\left(k=V_{\mathrm{S}} / V_{\mathrm{M}}\right)$. 


\section{CANDIN LITEANU AND SIMION GOCAN}

The distribution coefficient $\alpha$ can be defined as the ratio of the substance activity in the stationary $a_{\mathrm{S}}$ to mobile $a_{\mathrm{M}}$ phases, viz.

$$
\alpha=a_{\mathrm{S}} / a_{\mathrm{M}}=\exp \left(\mu_{0 \mathrm{M}}-\mu_{0 \mathrm{~S}}\right) / R T
$$

where $\mu_{0 \mathrm{~S}}$ and $\mu_{0 \mathrm{M}}$ are the standard chemical potentials in the stationary and mobile phases. Since the standard chemical potential of the substances in a mixture differ: $\mu_{01} \neq \mu_{02}$, etc. it follows that $\mu_{1} \neq \mu_{2}$, etc., hence the impossibility of two substances having similar displacement velocities along a chromatographic column.

In fact, if $\alpha_{1} / \alpha_{2} \rightarrow 1$ the displacement velocities of the two substances will differ by a very small factor requiring very long separation columns, which is an obvious major practical inconvenience.

Thus, one can easily see that the more numerous and diverse the factors affecting the displacement velocities, such as reproducibility of the distribution equilibrium. the easier will be the separation of the mixture constituents, and shorter columns will be required.

As the two-phase distribution equilibrium is governed by a set of parameters (temperature, $\mathrm{pH}$, ionic strength, polarity, etc.), we can write

$$
\alpha=\mathfrak{f}(a, b, c, \ldots)
$$

Likewise

$$
k=\mathrm{f}\left(a^{\prime}, b^{\prime}, c^{\prime}, \ldots\right)
$$

and obviously

$$
v=\mathrm{f}\left(a, a^{\prime}, b, b^{\prime} \ldots\right)
$$

Considering the parameters governing displacement along the column we may have: (1) steady-state chromatography and (2) unsteady-state chromatography. In the latter case, one or several variables governing the two-phase distribution may be time-dependent, say

$$
a=\mathrm{f}(t), \quad b=\mathrm{f}(t), \ldots
$$

respectively, and so

$\mathrm{d} a / \mathrm{d} t \neq 0$ (gradient of variable $a$ ),

$\mathrm{d} b / \mathrm{d} t \neq 0$ (gradient of variable $b), \ldots$

Let us write $\mathrm{d} a / \mathrm{d} t=k$ for a constant gradient of variable $a$ and $\mathrm{d} a / \mathrm{d} t=\mathrm{f}(t)$ for a changing gradient of variable $a$, which changes as a function of time.

The steady variation of the chromatographic variables can be linear or in the shape of a curve with its branches pointing downward (concave gradient) or upward (convex gradient) or even assuming a more intricate pattern (compound gradient). The continuous variation of a variable (discontinuous gradient) can be approximated by a continuous curve. If elution is considered, it is called gradient elution and stepwise elution ${ }^{1}$. The above statements are illustrated in Figure 1.

The use of gradients is the only general method allowing for a substantial differentiation among the displacement velocities of the various substances in a mixture along a column. Gradient chromatography is now being developed to open up new prospects for this separation method. 
The use of the gradient is a basic element for the optimization of the chromatographic process, a major issue of chromatography. However, in this case optimization takes place during the separation process itself, unlike conventional chromatography wherein optimization is by selecting the most suitable variables and maintaining them unchanged during the chromatographic process. It must be borne in mind that in the separation of complex

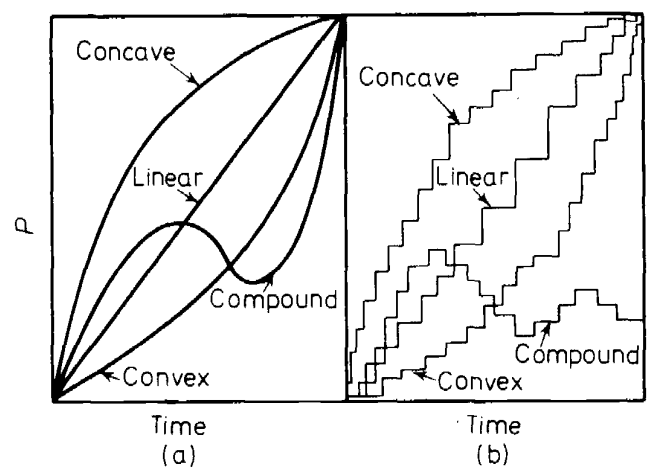

Figure 1. The classitication of gradients according to their shape ${ }^{1}$.

substances, conventional chromatography fails to yield an appropriate resolution in every case. Thus, gradient chromatography was developed out of practical necessities.

\section{TYPES OF GRADIENTS}

In keeping with Stahl's principle ${ }^{2}$ a classification of gradient chromatography can be made, according to the phases of the chromatographic process where certain properties or some of their combinations are changed:

Mobile phase gradients: concentration

polarity

$\mathrm{pH}$

ionic strength

Stationary phase gradients: composition

impregnation

activity

Medium gradients: temperature

vapour tension

flowrate

grain size

cross section

layer thickness

Combined gradients: vapour composition/concentration concentration/layer thickness

temperature $/ \mathrm{pH}$ 


\subsection{Mobile phase gradients}

The appearance for the first time of the mobile phase gradients can be readily accounted for since it is easier to induce a steady or stepwise variation of a certain property of the mobile phase (of the eluent) than of the stationary phase or of the medium.

In the following, a brief survey will be made with due regard to the chronology of the papers written on the subject and their grouping according to their various fields of application and working techniques.

As pointed out by Synge ${ }^{3}$, the idea of gradient is ascribable to Tiselius. Concomitantly, Mitchell and co-workers ${ }^{4}$ used the concentration and $\mathrm{pH}$ gradient technique in the paper chromatographic separation of certain enzymes. In the years following, an outstanding contribution to the development of gradient chromatography was made by Tiselius's followers, Alm ${ }^{3,6}$, Williams ${ }^{7,8}$ and Hagdahl $l^{9}$. and to its theoretical substantiation and its practical application as well. At the same time Donaldson and co-workers ${ }^{10}$ were using the principle of the elution gradient (specifically, a polarity gradient) for the separation of organic acids-without calling it a 'gradient'. Strain ${ }^{11}$ used a sorption gradient, while Busch and co-workers ${ }^{12-14}$ and Mader $^{15}$ were using the gradient elution technique for the separation of organic acids. Several papers were published covering different domains and using different techniques. Lederer ${ }^{16}$ used the elution gradient for the separation of cations. whereas Grande and Beaukencamp ${ }^{17}$ used it in the separation of inorganic anions. Bannister and his colleagues ${ }^{18}$ applied the gradient elution technique to polymer fractionation. Gradient elution technique has proved successful in the separation of biological substances.

In 1962 the first works of Wieland and Determann ${ }^{19}$ and Rybicka ${ }^{20}$ appeared showing the possibility of using elution gradients in thin-layer chromatography. Stimulated by those early successes, Niederwieser and Honegger $^{21,22}$ took a keen interest in the development of that technique, and made a comprehensive exposition of gradient techniques in thin-layer chromatography ${ }^{23}$.

\subsection{Stationary phase gradients}

Stationary phase gradient chromatography developed later due to technical difficulties involved in column filling and preparation of thin-layer plates with a view to getting reproducible results. An important contribution was made by Stahl et al. ${ }^{2,24-26}$ who worked out technical processes and the devices required to obtain the stationary phase gradient.

Composite gradients ${ }^{2,26-29}$, impregnation ${ }^{2,26,28}$ and activity ${ }^{30}$ gradients were used to achieve even better separations.

\subsection{Medium gradients}

The temperature gradient in open-column chromatography was introduced by Liteanu and Gocan ${ }^{31}$ in 1961 and recently extended to closedcolumn chromatography ${ }^{32}$. Hesse and Engelhardt ${ }^{33}$, as well as Maggs and Young ${ }^{34,35}$ used temperature programming in liquid-solid chromatography.

The possibility of using flow programming in column chromatography to cut down analysis time without adversely affecting resolution was shown 
by Scott and Lawrence ${ }^{36}$. A certain flowrate control in thin-layer chromatography could be achieved with a grain-size gradient ${ }^{13}$.

Layer-thickness gradients were also made use of in research by Abbot and Thomson ${ }^{28}$ and by Stahl ${ }^{37}$.

In 1966 Drapon and Guilbot ${ }^{38}$ used a mobile phase evaporation gradient in paper chromatography, while in 1968 Turina and co-workers ${ }^{39}$ used an adaptor for solvent evaporation during development in thin-layer chromatography yielding better resolutions.

De Zeeuw studied the part played by solvent vapours in thin-layer chromatography ${ }^{40,41}$ developing a programmed vapour working technique $^{42-44}$. Geiss and co-workers ${ }^{45}$ investigated the separation of some organic substances by thin-layer chromatography with activity gradient (programmed vapours).

\subsection{Compound gradients}

Niederwieser ${ }^{46}$ suggested a nomenclature of the gradient direction versus that of eluent flow (Figure 2). Previously Niederwieser and Honegger ${ }^{23}$ pointed out the existing possibilities when combining two gradients, e.g.

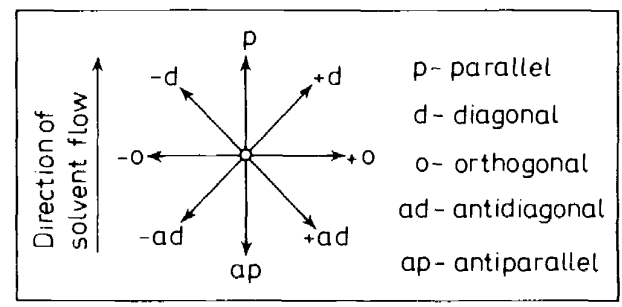

Figure 2. The classification of gradients according to direction ${ }^{46}$.

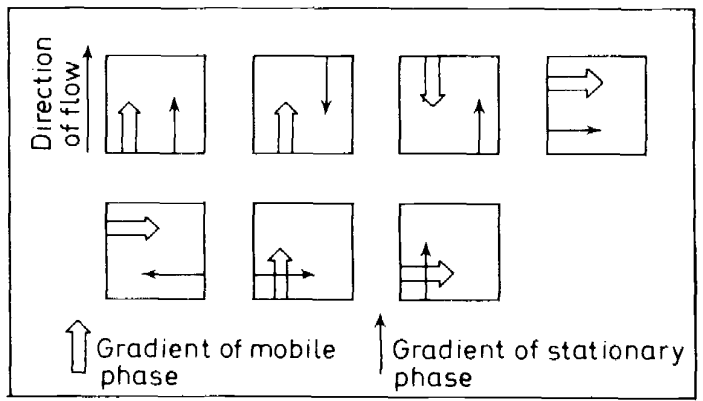

Figure 3. The possibilities of combining two gradients ${ }^{23}$.

mobile and stationary phase gradients for thin-layer chromatography (Figure 3). Indeed, many other gradient combinations might exist : medium gradients with mobile or stationary-phase gradients ${ }^{47}$, etc. 


\section{APPARATUS FOR OBTAINING GRADIENTS}

\subsection{Apparatus for obtaining mobile phase gradients}

The problem of devices to yield gradients was tackled and systematically analysed in several survey articles ${ }^{2.23 .48,49}$. Mobile-phase gradient devices were grouped according to the gradient shape : exponential, linear, parabolic, continuous or stepwise.

\subsubsection{Device for obtaining mobile phase exponential gradients}

This device consists of a mixing vesse ${ }^{19}$ assuming various shapes and a reservoir $(\mathrm{R})$ above. There are other types, too, including three vessels placed one above the other, two of which are mixing vessels. Because of its simplicity, the system was widely used. The various devices are essentially similar, which is the reason for selecting only one single illustrative apparatus for each separate group. Figure 4 shows two devices yielding mobile phase exponential gradients. In these devices, the composition (concentration) of the solvent in the mixing vessel (M) tends, according to an exponential law, to the composition in the reservoir above $(R)$.

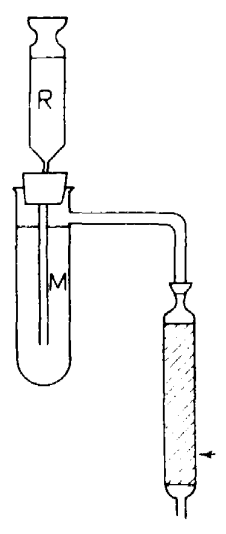

(a)

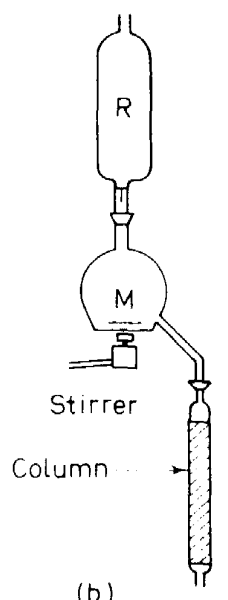

(b)

Figure 4. Gradient elution devices.

Cherkin and co-workers ${ }^{50}$ have evolved a relation for the device in Figure 4(a) assuming the form

$$
c=c_{0}\left(1-1 / \mathrm{e}^{k}\right)
$$

where $c$ denotes concentration of the solution flowing out of the mixing $\operatorname{vessel}(\mathrm{M}), c_{0}$ is the concentration of the solution in the reservoir $(\mathrm{R}), k=V / V_{\mathrm{M}}$, with $V$ as the volume of the eluent which passed through the column, while $V_{M}$ is the volume of the mixing vessel (M). In Figure 5 equation 6 has been plotted. Warner and Lands ${ }^{51}$ have developed a nomographic expression for the eluent composition in a constant volume vessel assuming a twocomponent system. 
SOME ASPECTS OF SOLUTION CHROMATOGRAPHY WITH GRADIENTS

Bock and Ling ${ }^{52}$, Drake ${ }^{53}$ and Lebreton ${ }^{48}$ have evolved a more general equation applicable to the devices in Figure 4 which assumes the form

$$
c=c_{2}-\left(c_{2}-c_{1}\right) \mathrm{e}^{-V / V_{M}}
$$

where $c$ is the eluent concentration at entry, $c_{1}$ is the solution concentration in the mixing vessel $(\mathrm{M}), c_{2}$ solution concentration in the reservoir $(\mathrm{R}), V$ the

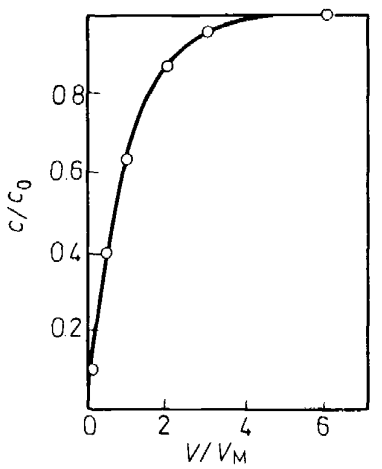

Figure 5. The plot of $c / c_{0}$ versus $V / V_{M}{ }^{51}$.

volume of eluent flowing out, and $V_{\mathrm{M}}$ denotes the volume of liquid in vessel (M) - which is constant.

Bendich and co-workers ${ }^{54}$ developed apparatus consisting of three superposed vessels illustrated in Figure 6(a), while in Figure 6(b) the molarity of sodium chloride was plotted in terms of the effluent volume for one or two, respectively, mixing vessels $(\mathrm{M})$.

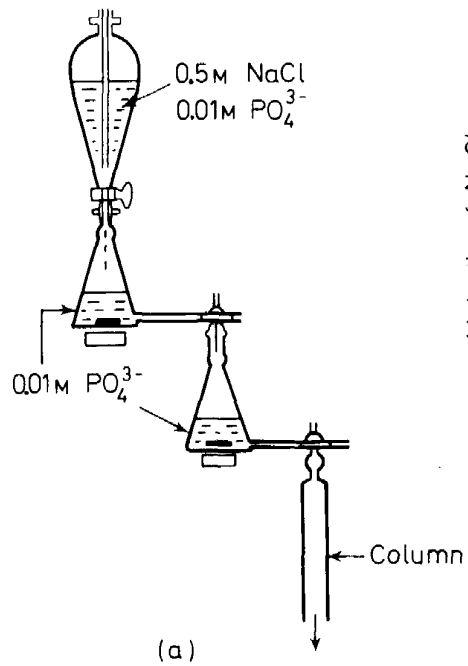

(a)

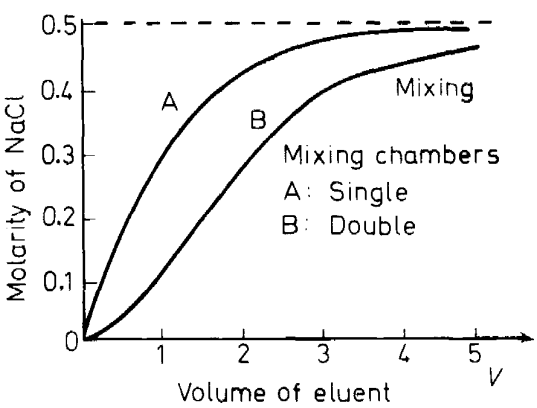

(b)

Figure 6. Diagram of the apparatus used for gradient elution with two mixing chambers. The inset shows the change of solution concentration as a function of the volume of eluent ${ }^{54}$. 


\section{CANDIN LITEANU AND SIMION GOCAN}

Another group of devices ${ }^{5-57}$ yielding a mobile phase gradient includes two vessels, of which one is a mixing vessel $(\mathrm{M})$ and the other a reservoir $(\mathrm{R})$ as illustrated in Figure 7. In this case the solvent is circulated by an on-line pump or by air or nitrogen pressure. Pressure is recorded as a function of eluent flow.

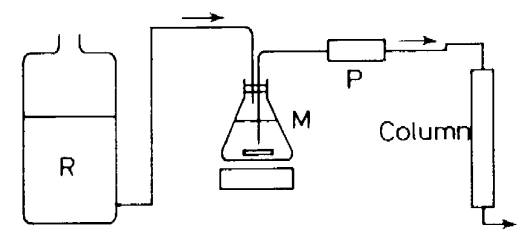

Figure 7. Arrangement for obtaining concentration gradients.

Niederwieser and Honegger ${ }^{23}$ offer a description of a device consisting of six closed chambers (1-6) communicating among themselves at their lower ends. To ensure a constant flowrate, the principle of Mariotte's vessels is applied, the flowrate being governed by the capillary (C) diameter. The chambers are emptied in turn starting with No. 6, followed by No. 5 and so on to the complete removal of the solution from the whole set of chambers (Figure 8).

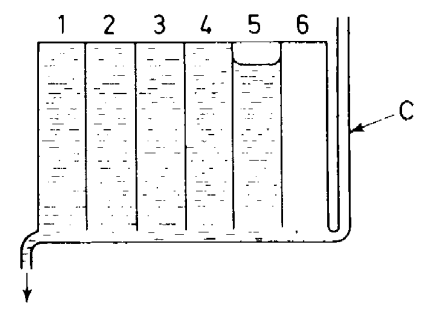

Figure 8. Scheme of a battery with closed mixing chambers for obtaining concentration gradients ${ }^{23}$.

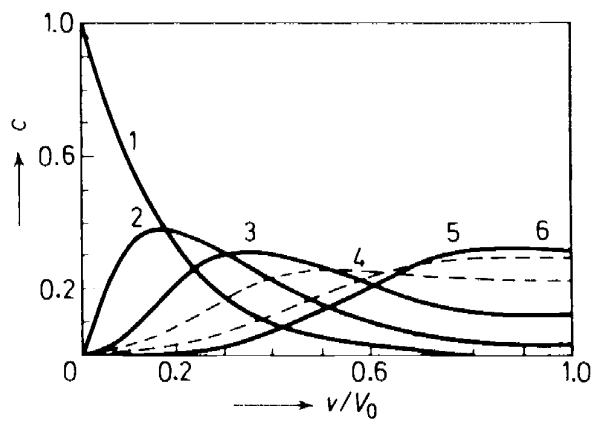

Figure 9. Experimentally determined concentration gradients from a mixing battery with six closed chambers (Figure 8). The number on the curve indicates the number of the chamber containing solution of concentration $L$. 
In this system the gradient curves assume an obvious exponential shape. Figure 9 illustrates the concentration variations of the solution flowing out of the chambers in terms of the ratio of the volume of solution flowing $(v)$ to total volume $(V)$ when initial concéntration $L$ exists in various chambers as marked on the figure, the rest of the chambers being filled with pure solvent. The curves were plotted after solution extinction had been measured. By

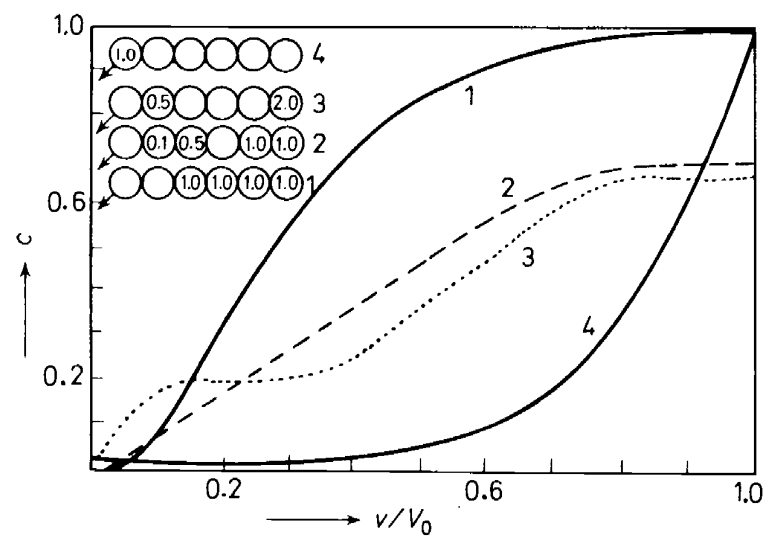

Figure 10. Some possible gradients obtainable by closed mixing chambers (Figure 8); superpositions of curves from Figure 9.

adding a number of chambers with a given initial concentration to the sixchamber system, different shapes of the gradient are obtainable. Figure 10 shows four combinations of the set with the initial (molar) concentrations of the respective chambers ${ }^{23}$.

\subsubsection{Apparatus yielding linear and parabolic gradients}

The mixing vessel $(M)$ and the reservoir $(R)$ are communicating vessels and the liquid therein is in hydrostatic equilibrium. They are connected either directly or through a siphon. Several types are distinguished, according to the shapes of the vessels.

Figure 11 shows the device described by Kenyon and co-workers ${ }^{58}$ for a system of two cylindrical vessels containing (fully miscible) solutions of similar densities. The polar solvent fraction in the vessel $(\mathrm{M})$ will rise steadily owing to the more polar solvent flow from reservoir $(\mathrm{R})$, expressed by equation

$$
X_{\mathrm{M}}=X_{\mathrm{R}}-X_{\mathrm{M}}\left[1-V_{\mathrm{c}} /\left\{V_{\mathrm{R}}^{0}+V_{\mathrm{M}}^{0}\right\}\right]^{V_{\mathbf{R}}^{0} / V_{\mathrm{M}}^{0}}
$$

where $X_{\mathrm{R}}$ is the polar solvent fraction in vessel (R), $X_{\mathrm{M}}$ is the polar solvent fraction in vessel $(\mathrm{M}), V_{\mathrm{M}}^{0}$ is the initial volume of the solvent in vessel (M), $V_{\mathrm{R}}^{0}$ is the initial volume of the solvent in vessel $(\mathrm{R})$, and $V_{\mathrm{c}}$ is the volume of solvent flowing out of the system into the column. With two similar vessels having the same volume and shape, a linear gradient results.

Devices connected by a siphon can readily be made and used with vessels 


\section{CANDIN LITEANU AND SIMION GOCAN}

of various shapes to get whatever gradients are sought. The device of Kellie and Wade ${ }^{59}$ is illustrated in Figure 12.

Snyder and Warren ${ }^{60}$ obtained various shapes of vessels by introducing cylindrical solid bodies into the reservoir B (Figure 13). For the general case of unequal densities the following relation was evolved by Wren ${ }^{61}$ for the arrangement of Figure 13

$$
V_{\mathrm{M}}=\left[1-\left(a V / V_{\mathrm{M}}^{0}\right)\right]^{(1-a) / a}
$$

where

$$
a=\left(A_{\mathrm{M}} / A_{\mathrm{R}}\right) /\left[\left(A_{\mathrm{M}} / A_{\mathrm{R}}\right)+\left(\mathrm{d}_{\mathrm{M}} / \mathrm{d}_{\mathrm{R}}\right)\right]
$$

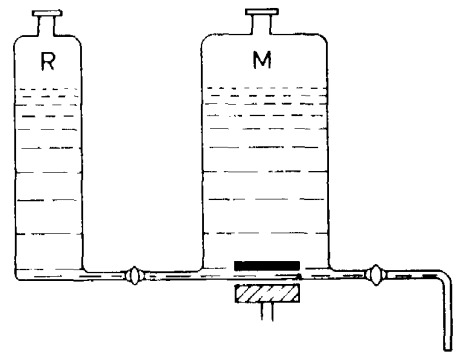

Figure 11. Gradient elution system ${ }^{58}$

Here $V_{M}$ is the solvent volume in reservoir $M$ before elution is started, $V$ is the eluent volume, $V_{M}$ the volume fraction of eluent $M$ in the binary mixture, $A_{\mathrm{M}}, A_{\mathrm{R}}$ are cross sectional areas of the vessels, $\mathrm{d}_{\mathrm{M}}, \mathrm{d}_{\mathrm{R}}$ are the densities of eluent $\mathrm{M}$ and $\mathrm{R}$.

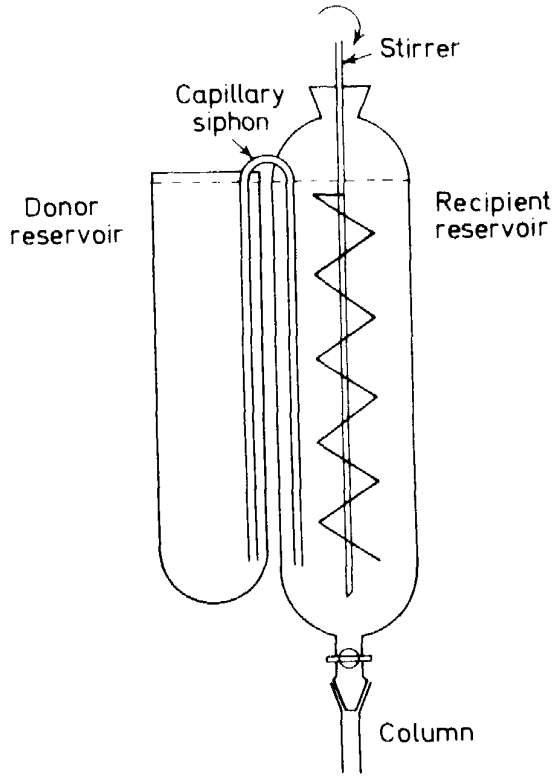

Figure 12. Gradient elution apparatus ${ }^{59}$. 
For the arrangement of Figure 14, where the inner vessel (2) is conical, Bock and Ling ${ }^{52}$ suggested a parabolic law (a), whereas for a profile of vessel (2), paraboloidal in shape, a linear law (b), as illustrated in Figure 15, seems preferable.

Also a number of gradient-yielding devices of definite shapes were imagined and developed. Peterson and co-workers ${ }^{62,63}$ made up a system of nine open chambers communicating among themselves in two ways (Figure 16),

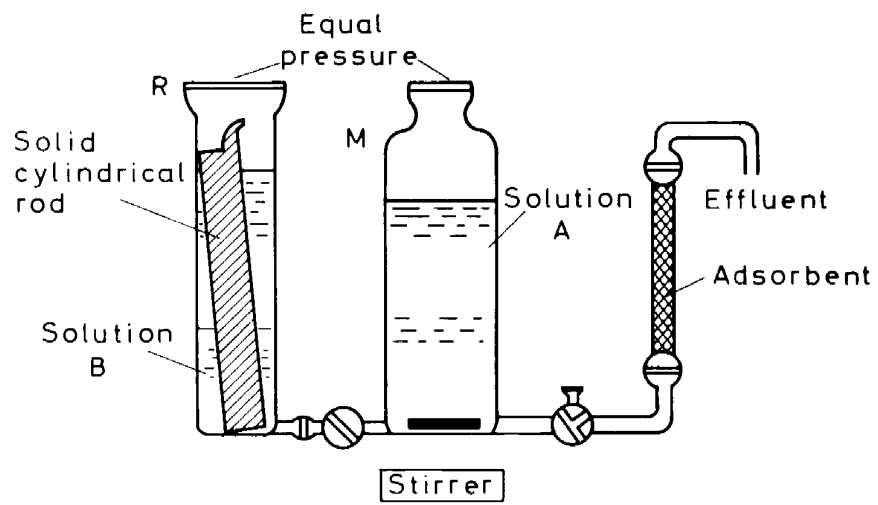

Figure 13. Gradient elution apparatus ${ }^{60}$.

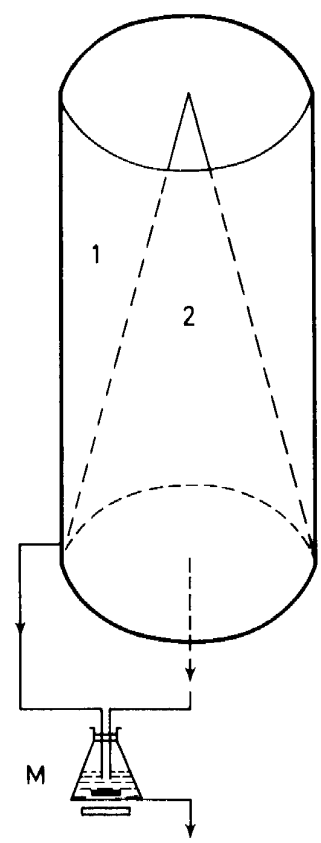

Figure 14. Gradient elution apparatus ${ }^{52}$. 


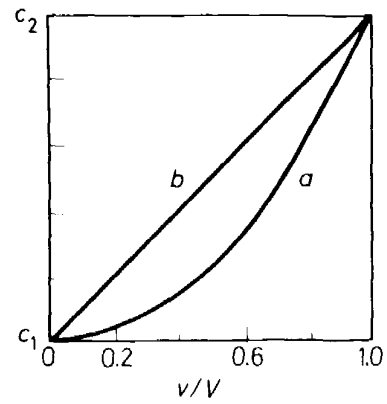

Figure 15. The gradient produced by apparatus from Figure 14.
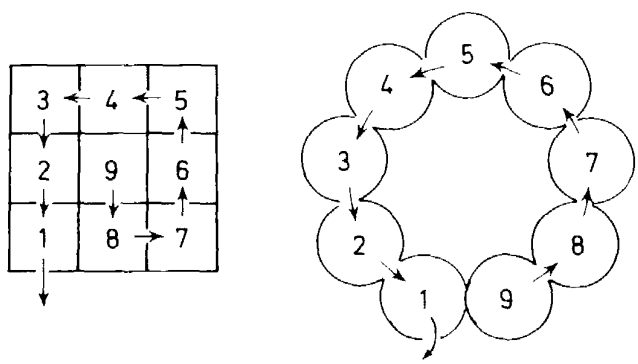

Figure 16. Two arrangements of mixing chambers ${ }^{\mathrm{t} 2,63}$.

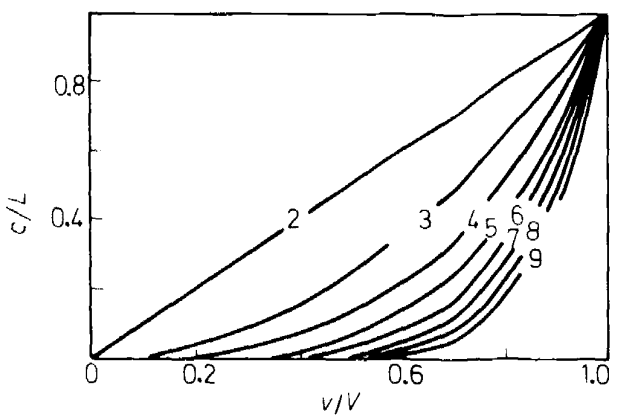

Figure 17. Gradients produced by several systems with solution of concentration $L$ in the chamber with number indicated on the curve (Figure 16). Other chambers contain water ${ }^{62}$.

the arrow showing the direction of flow of the solutions at hydrostatic equilibrium. This device yields gradients of various shapes, which may be convex, concave, linear, etc. If the solution of $L$ (this being the limiting concentration) is admitted into the last chamber of a given combination, the rest being filled with water, the concentration $c$ of the liquid flowing out of the first chamber will change as seen in Figure $17^{62}$, the figure on the plot shows the location of the chamber containing the solution of concentration 
$L$. For instance, with the solution of concentration $L$ in chamber 2 , a system of two communicating chambers of equal volumes was formed, hence the resulting linear gradient. With the solution in chamber 3-a three-chamber system is formed - the gradient became concave in shape. The greater the number of chambers, the stronger the curve concavities. Figure 18 illustrates the contribution of one single chamber to a nine-chamber system.

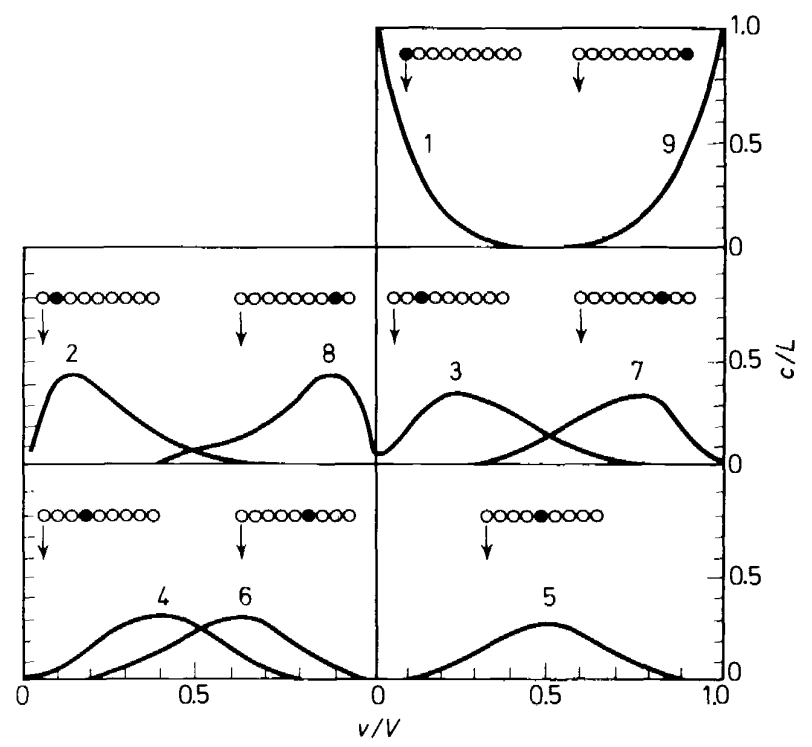

Figure 18. Single-chamber contributions in nine-chambered system (Figure 16). Blacked-in circles represent the position of solution $L$, other chambers are filled with water.

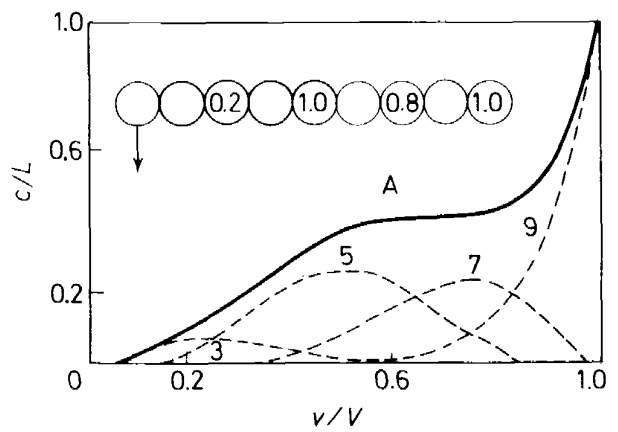

Figure 19. Formation of a compound gradient (curve A) by summation of the contributions of lour chambers in a nine-chambered system, Figure 16 (curves 3, 5, 7 and 9). Numbers within circles represent concentrations (molar). Other chambers contain water.

With this device gradients summing up the contributions of a larger number of chambers within the nine-chamber system can be obtained (Figure 19). The figures stand for the contribution of the solution of specific 
molar concentration in the respective reservoir to the eluent concentration variations. The full curve corresponds to the case when all four reservoirs are operating (compound gradient) and one can easily observe that the shape of the resulting curve depends on the number of chambers and the concentration of the solution in each separate chamber. Assuming only nine solutions of different concentrations distributed in as many ways as possible, 986409 gradients could be obtained.

Obviously. the range of devices yielding mobile phase gradients is far wider but in the description above we confined ourselves to the most representative types in this group. Today automatic devices are being made yielding various programmed gradients $(\mathrm{pH}$, polarity, etc.).

\subsection{Apparatus yielding solid stationary-phase gradients}

Stahl $l^{2}$ describes a column-filling device consisting of a chamber divided into two compartments $\mathrm{A}_{1}$ and $\mathrm{A}_{2}$ by a wall $\mathrm{B}$ diagonally placed (Figure 20).

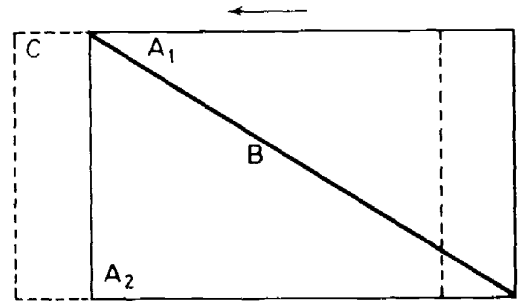

Figure 20. Chamber with two compartments for obtaining gradients of column packing ${ }^{2}$.

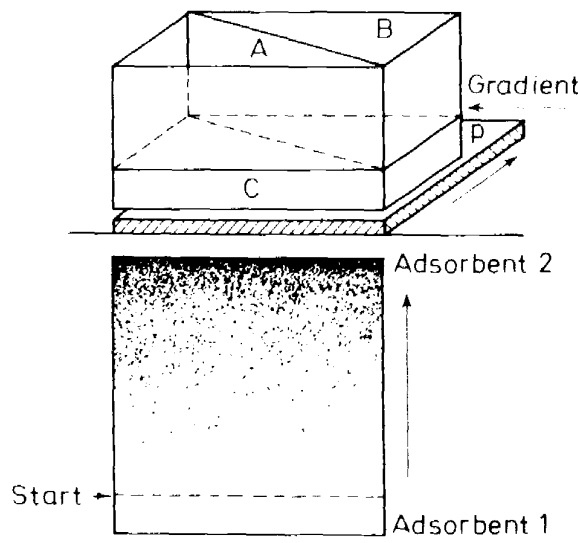

Figure 21. Diagram of apparatus for obtaining layers with composition gradient ${ }^{24}$.

A sliding chamber wall $\mathrm{C}$ allows for different amounts of the two types of adsorbants to fall into a mixing chamber from where they are carried continuously into the chromatographic column. For instance, basic and acidic 
aluminium trioxide $\left(\mathrm{Al}_{2} \mathrm{O}_{3}\right)$ of similar grain-size were the two kinds of adsorbents.

The question of thin-layer gradient manufacture was solved by Stahl ${ }^{24}$ who developed a mechanical device working in practice on the same principle. It consists of a parallelepipedic trough to which a separating wall was fitted diagonally. Into the two dimensions $\mathrm{A}$ and $\mathrm{B}$ the two adsorbent suspensions were introduced. The trough was placed over a mixing chamber $C$ equipped with an electrically driven plate mixer. The control of the layer thickness was identical with that for the common thin-layer laying devices (Figure 21).

\subsection{Apparatus for medium gradients}

3.3.1. Devices for the temperature gradient

The temperature gradient combined with the elution gradient were used by Baker and Williams ${ }^{64}$ in polymer fractionation by chromatographic techniques. The whole installation is shown schematically in Figure 22.

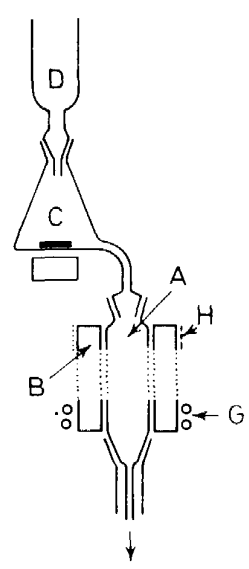

Figure 22. Diagram of apparatus for elution and temperature gradient ${ }^{64}$.

The main parts of the installation are column A, the metal jacket $\mathrm{B}$, the mixing vessel $\mathrm{C}$ producing the solvent gradient, the solvent reservoir $\mathrm{D}$ and the siphon leading to the fraction collector. The metal jacket $B$ is a $\mathbf{3 0}$ $\mathrm{cm}$ long aluminium tube; at its top the temperature $t_{2}=60^{\circ} \mathrm{C}$ is achieved by a resistance $\mathrm{H}$, whereas at the bottom the temperature $t_{1}=10^{\circ} \mathrm{C}$ is controlled by a copper spiral $\mathrm{G}$ through which water is circulated.

In a recent work, Liteanu and Gocan and their colleagues ${ }^{32}$ applied the temperature gradient in a closed column to ion-exchange chromatography. The temperature gradient was developed by the device in Figure 23. It consists of a copper tube (1) whose inner diameter is roughly equal to the glass column (2) outer diameter. At either end the metal tube is fitted with circular chambers $\mathrm{a}$ and $\mathrm{b}$ through which thermostatically controlled water at temperature $t_{1}$ is circulated to the lower chamber and at temperature $t_{2}$ 
in the upper chamber $\left(t_{2}>t_{1}\right)$. The glass tube (2) has at its lower end a glassfrit (3) on which the ionite (4) is placed.

As we know from the theory of heat conductivity in a metal bar with the temperatures $t_{1}$ and $t_{2}$ at its ends $\left(t_{2}>t_{1}\right)$, the temperature along the bar decreases from $t_{2}$ to $t_{1}$, according to an exponential law of the form $t=t_{2} \mathrm{e}^{-a z}$, where $a$ is a constant given by $\{a p / \lambda S\}^{\frac{1}{2}}, \alpha$ being the outer bar conductivity,

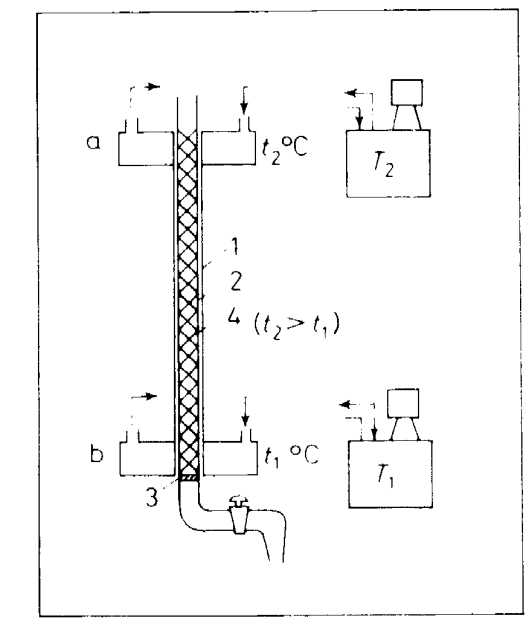

Figure 23. Column with temperature gradient ${ }^{32}$.

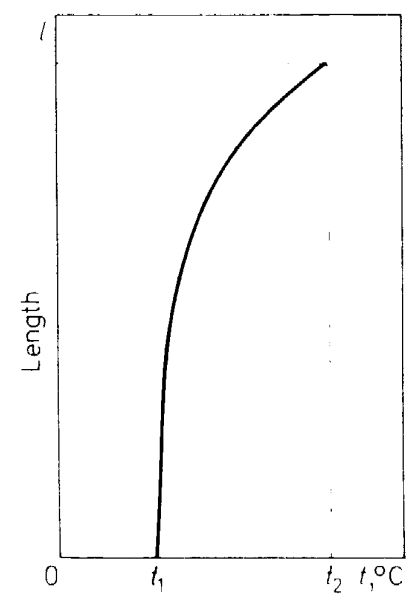

Figure 24. The temperature variation along the column L. (Figure 23).

$p$ the bar perimeter, $\lambda$ thermal conductivity of the bar, and $S$ the bar cross section. Temperature variations along the column are shown in Figure 24, thus giving rise to the exponential law governing the temperature gradient variations. 
After a number of successful attempts to use the temperature gradient for open-column (paper or thin-layer) chromatography, Liteanu and Gocan ${ }^{65}$ have passed on to the design of a chromatographic chamber whose size was similar to that of ordinary ones, Figure 25.

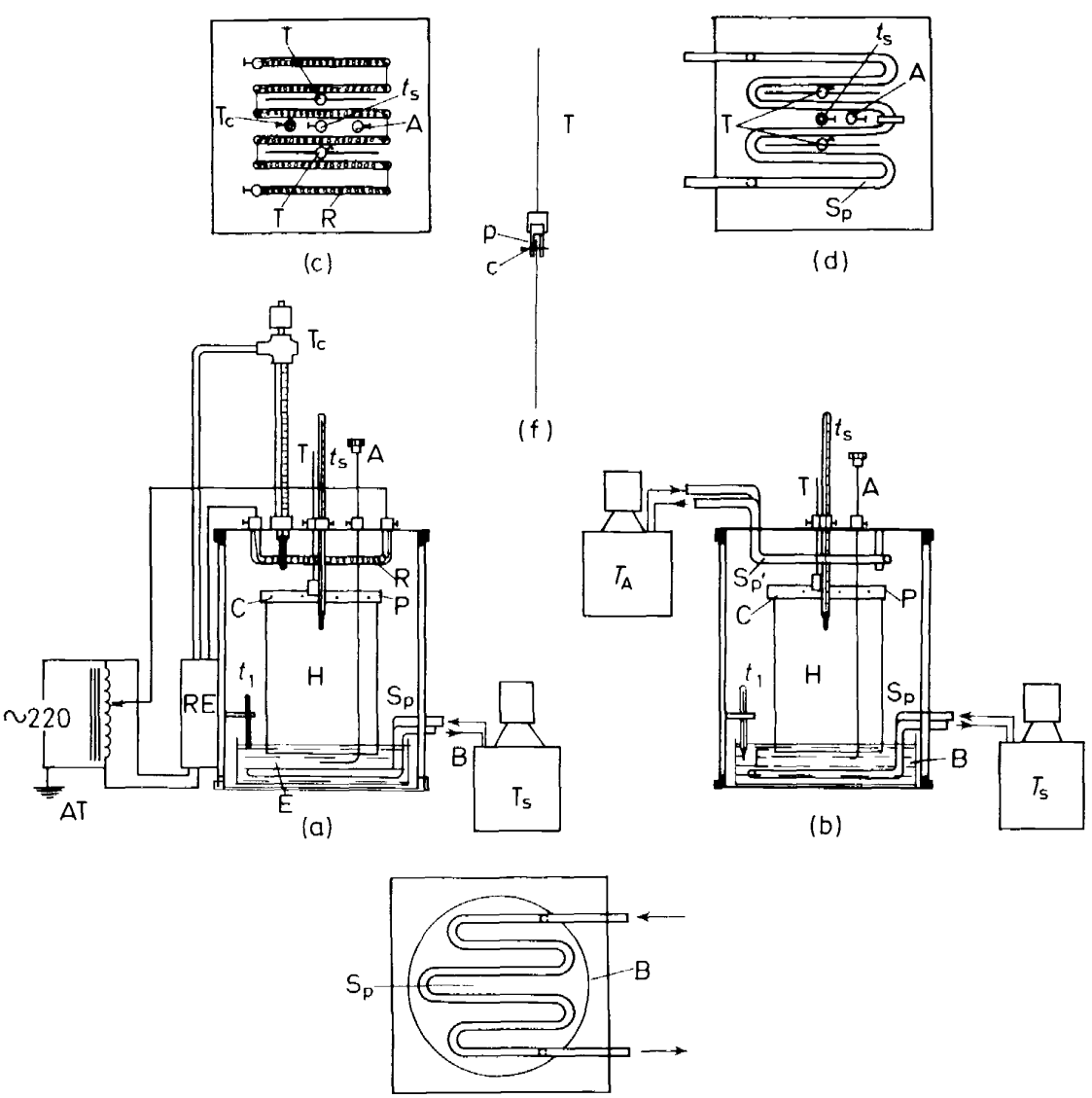

(e)

Figure 25. Chromatographic chamber (Plexiglas) of great capacity with temperature gradient ${ }^{65}$. a-Electric thermostation at top; $\mathrm{T}_{\mathrm{c}}$ - Contact thermometer; $\mathrm{R}$ - Electric resistance; $\mathrm{RE}$ electromagnetic relay; AT - Autotransformer; $b$ - Thermostation with water at top; $c$ - Lid of chamber $a$; $d$ - Lid of chamber $b$; e-Recipient $b$ for eluent; $f$ - fixation system for paper or plate $\mathrm{H}(\mathrm{P}$-plexi-bar, C-plexi-nail).

The chromatographic chamber is a two-walled quadratic prism whose side walls are made of Plexiglas. At its top and bottom sides it has two removable lids (Figure $25 \mathrm{a}$ and $\mathrm{b}$ ). Eluent $\mathrm{E}$ is in the vessel $\mathrm{B}$ on the bottom of which the spiral $\mathrm{S}_{\mathrm{p}}$ is also fitted in order that water may be circulated from the thermostat $\mathrm{T}_{\mathrm{S}}$ to maintain temperature at the constant value $t_{1}$ (Figure $25 \mathrm{e}$ ). 


\section{CANDIN LITEANU AND SIMION GOCAN}

In one case, top temperature was achieved by a thermostatically controlled device consisting of a contacting thermometer $T_{c}$, one electromagnetic relay $\mathrm{RE}$ and one electric resistance $\mathrm{R}$ (Figure $25 \mathrm{c}$ ). Top temperature is measured by a thermometer $\mathrm{t}_{\mathrm{s}}$.

In the other case. top temperature was reached by a spiral $S_{p}$ through which water from thermostat $\mathrm{T}_{\mathrm{S}}$ was circulated (Figure $25 \mathrm{~d}$ and b). Top temperature was measured on the control thermometer $t_{\mathrm{S}}$.

Obviously, inside the chromatographic chamber a vapour tension gradient occurs causing vapours to diffuse to the eluent surface where they condense. Due to these unsaturation conditions part of the eluent that has penetrated into the column (volume $V^{\prime}$ ) is evaporated $(\Delta V)$ so that we can write $V^{\prime \prime}=V$ $+\Delta V$, where $V$ is the volume of the eluent inside the column.

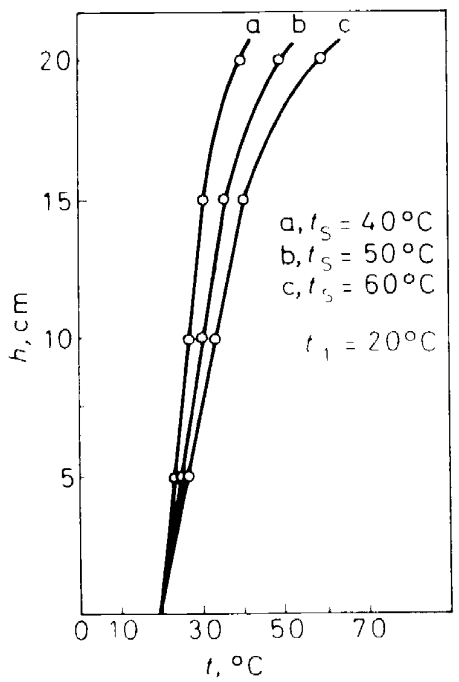

Figure 26. Temperature variation along the central axis of the chromatographic chamber with temperature gradient (Figure 25).

The thermal conditions inside the chromatographic chamber are illustrated in Figure 26 for three different cases.

\subsubsection{Device for the achievement of a layer-thickness gradient}

To this end, Abbot and Thomson ${ }^{28,66}$ have used a hand-operated thinlayer device in order to get wedge-shaped thin layers. These layers are produced by placing two wedges $\mathbf{B}$ under the suspension laying chamber, as illustrated schematically in Figure 27.

\subsubsection{Programmed vapour chamber}

This technique aimed at improving separations in thin-layer chromatography was initiated by De Zeeuw ${ }^{42-44}$. The programmed vapour chamber 
schematically illustrated in Figure 28 is divided into three parts by chromiumplated brass plates; it also comprises the ground plate (B) whereon the solvent reservoir (A) stands and a chamber (C) with 21 troughs.

In use, the troughs are filled with polar and non-polar solvent mixtures (S), polarity being higher with each consecutive solvent so as to form a gradient.
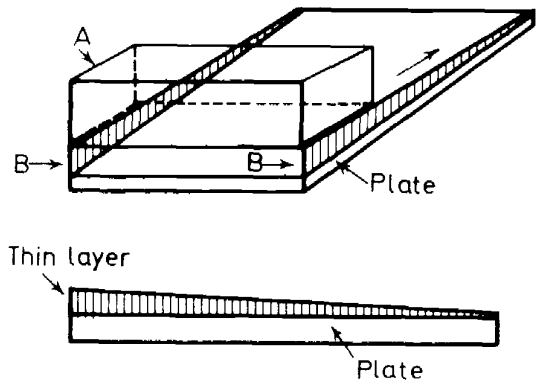

Figure 27. Diagram of apparatus for preparing wedge-layer plates ${ }^{28,66}$.

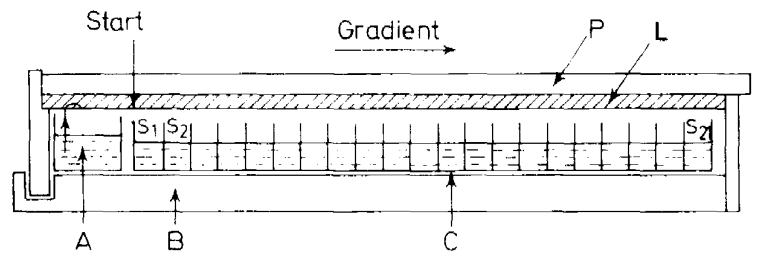

Figure 28. The vapour-programming chamber (longitudinal section) ${ }^{43}$.

The vapours of these solvents with a polarity gradient will balance off the absorbent in the chromatographic plate $P$ lying with the thin layer $L$ over the troughs. The eluent is filled into the reservoir A connected with the thin adsorbent layer by filter paper bands.

\section{SEVERAL RESULTS OBTAINED BY GRADIENT CHROMATOGRAPHY}

In order to illustrate the advantages of gradient chromatography over ordinary chromatographic techniques, a few illustrative achievements will be presented. The number of reports on the gradient technique is considerable and it is steadily increasing.

\subsection{Mobile phase gradients}

For the separation of $\mathrm{Ni}(\mathrm{II}), \mathrm{Mn}(\mathrm{II}), \mathrm{Co}(\mathrm{II}), \mathrm{Cu}(\mathrm{II}), \mathrm{Fe}(\mathrm{II})$ and $\mathrm{Zn}(\mathrm{II})$ metals as anionic complexes over a Dowex anion exchanging resin, a stepwise elution was used by Kraus and Moore ${ }^{67}$ by varying hydrogen chloride 


\section{CANDIN LITEANU AND SIMION GOCAN}

concentration within 12 to $0.005 \mathrm{~N}$, i.e. a stepwise concentration gradient was made use of (Figure 29 a). Figure 29 b shows the resulting elution curves.

This is a typical case in column ion-exchange chromatography since, as a rule, all of the mixture constituents can hardly be eluted with one single eluent, hence the more convenient continuous gradient operation versus the discontinuous gradient technique.

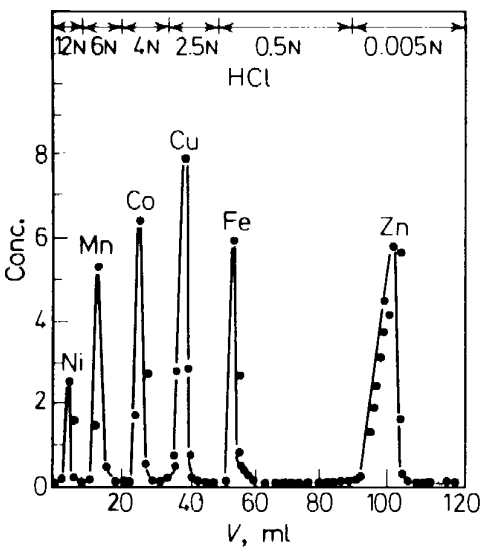

(a)

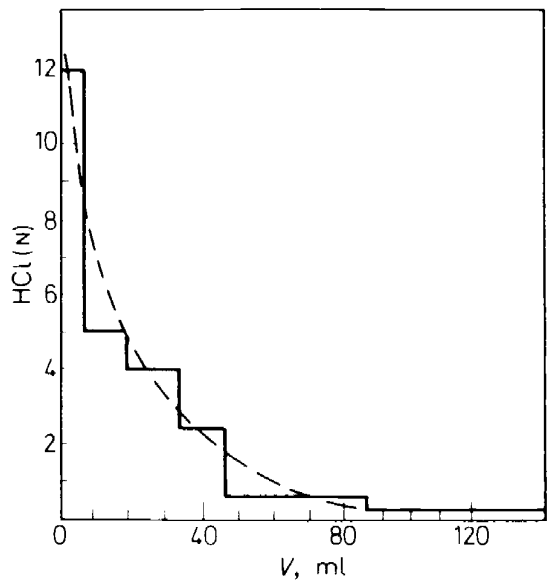

(b)

Figure 29. Elution curves and the shape of a stepwise elution curve ${ }^{67}$.

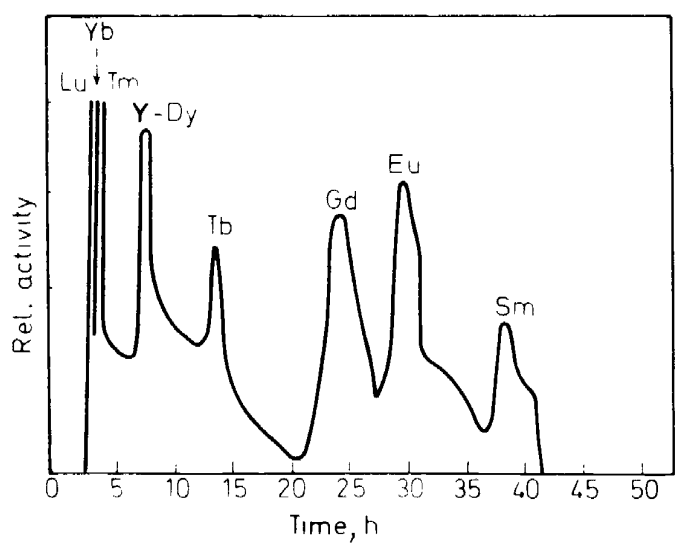

Figure 30. Elution curves at $\mathrm{pH}=3.19^{68}$.

The efficiency of $\mathrm{pH}$ gradient elution is illustrated by comparing Figure 30 without $\mathrm{pH}$ gradient and Figure 31 -with pH gradient ${ }^{68}$.

In the former case the peaks corresponding to the elements erbium and holmium are not visible, whereas the ones for lutetium, ytterbium and thulium show only very weak resolution. 


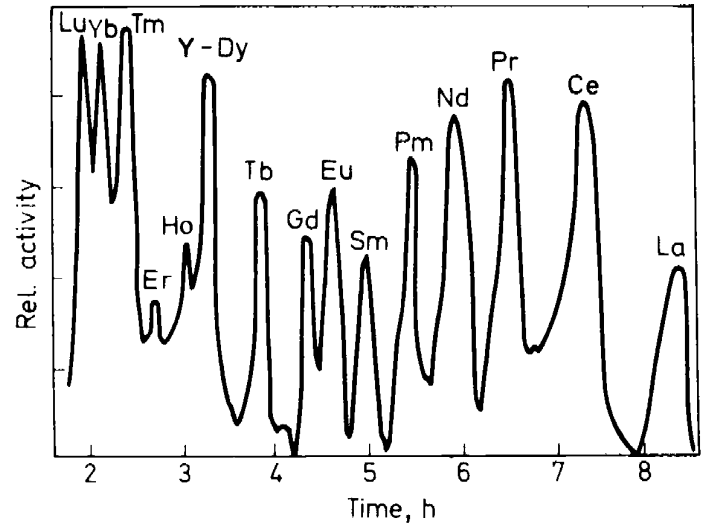

Figure 31. Elution curve with $\mathrm{pH}$ gradient (from $\mathrm{pH}=3.19$, with $0.107 \mathrm{pH}$ units $/ \mathrm{h})^{68}$.

\subsection{Stationary phase gradients}

The stationary phase orthogonal gradient opens up new possibilities for thin-layer chromatography, both in point of mixture separation, and in point of chromatogram zonal distribution.

Stahl $^{2}$ used the stationary phase composition orthogonal gradient (cellulose-silica gel) in thin-layer chromatography for the separation of amino acids using a butanol-acetic acid-water (50-10-40) mixture (Figure 32). The technique can be used for the separation of an unknown mixture, conclusions as to the importance of one or other layer constituents being inferred from the general aspect of the chromatogram. Still in Figure 32 one can see the much stronger colour reaction between amino acids and nonhydrin on silica gel than on cellulose.

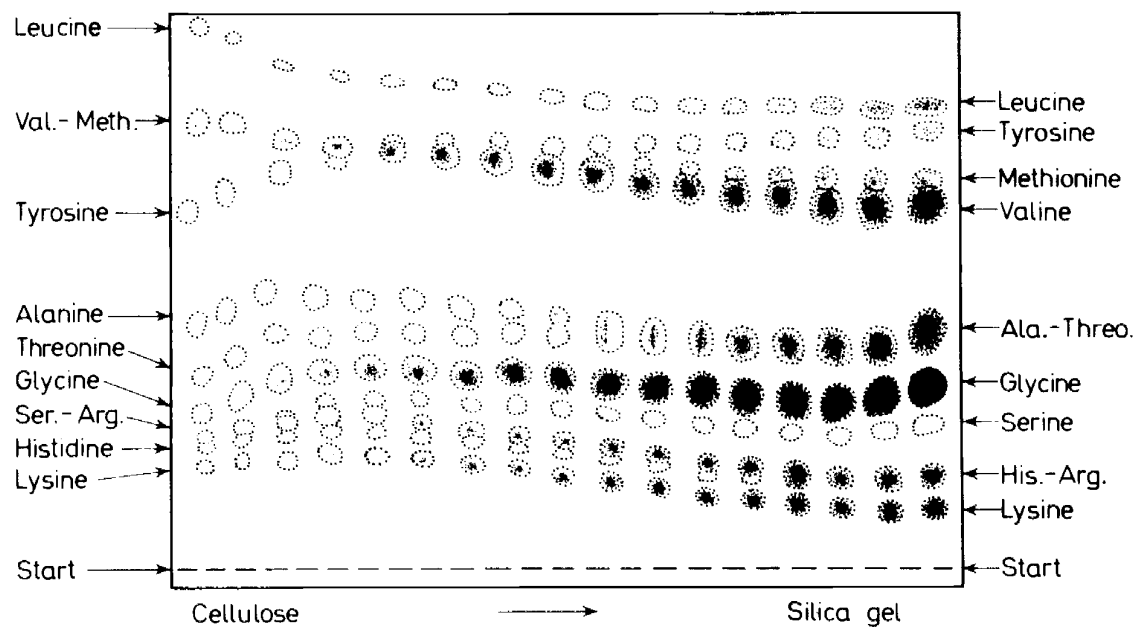

Figure 32. Separation of a mixture of amino acids on a thin layer with composition gradient (cellulose/silica gel) ${ }^{2}$. 


\section{CANDIN LITEANU AND SIMION GOCAN}

Similarly, the optimum impregnation degree of a thin layer can be readily assessed as pointed out by Stahl and Vollmann ${ }^{26}$ by an orthogonal gradient on a chromatographic plate. Figure 33 illustrates the separation of some terpenic alcohols on a silver nitrate $\left(\mathrm{AgNO}_{3}\right)$-impregnated silica gel layer. Optimum impregnation is found to correspond to a $2.5 \% \mathrm{AgNO}_{3}$ content of silica gel $\mathrm{H}$.

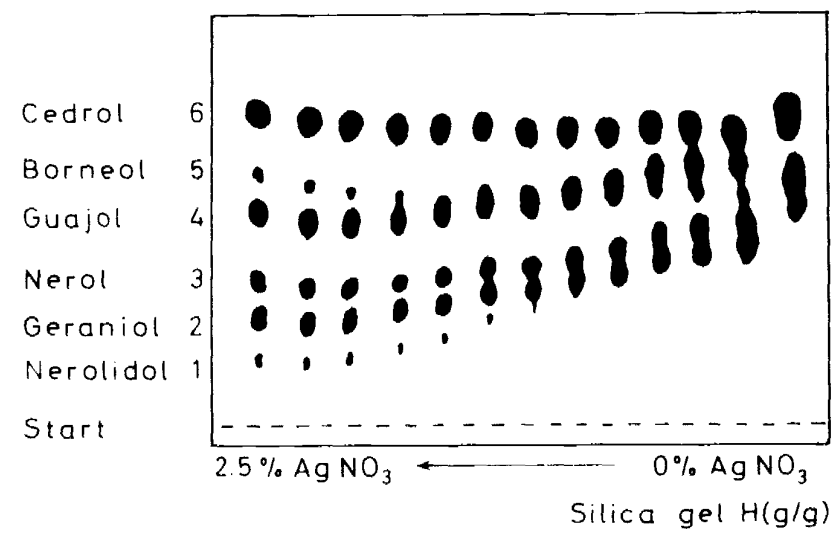

Figure 33. Separation of a mixture of terpenic alcohols on a thin layer with impregnation gradient ${ }^{26}$.

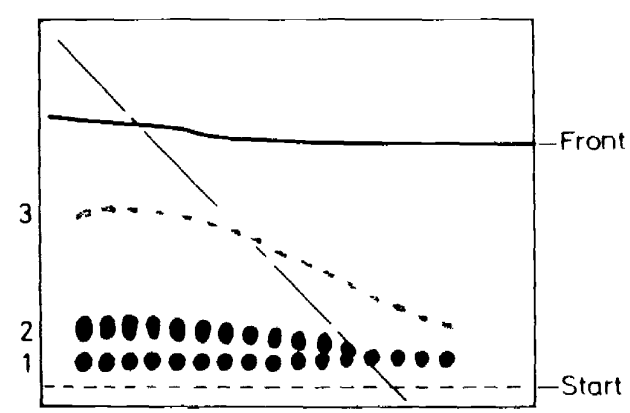

Figure 34. Separation of a mixture of squalene (1), cholesteryl stearate (2) and cholesterol (3) using an activity gradient on silica gel $G$. Solvent: heptane. The left side of the plate was immersed in a $25 \%$ aqueous acetone solution and activated at $110 \mathrm{C}^{30}$.

Honegger ${ }^{30}$ developed a thin-layer activity antidiagonal gradient as follows: a thin layer plate dipped into a 25 per cent water in acetone solution (part of the plate being the solution up to the diagonal line) for five seconds and then was activated at $110^{\circ} \mathrm{C}$ for 20 minutes. The results obtained thereby are shown in Figure 34.

These examples as well as those found in other papers are illustrative of the wide applicability of these gradient techniques. 


\subsection{Medium gradients}

The effect of the temperature gradient on an open paper and thinlayer chromatographic column was investigated by us in a number of reports ${ }^{31,65,69-82}$. Figures 35 to 45 inclusive illustrate some of these results concerning the $R_{f}$ value variations in terms of the temperature gradient for different substances and eluent systems.

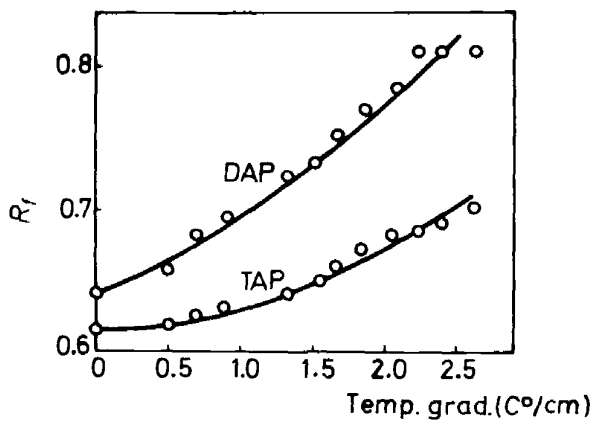

Figure 35. The plot of $R_{f}$ values versus temperature gradient for diamidophosphate (DAP) and triamidophosphate (TAP); thin layer of cellulose ${ }^{80}$.

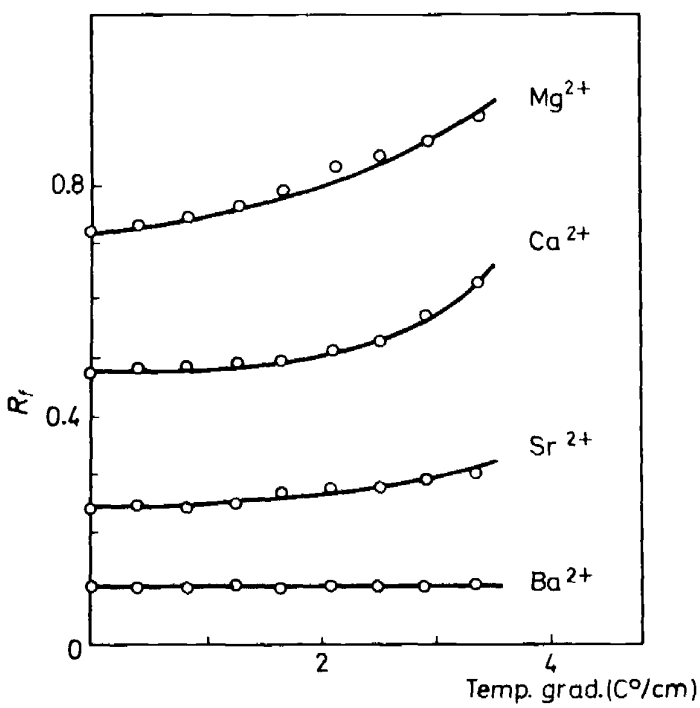

Figure 36. The plot of $R_{f}$ values versus temperature gradient for some alkaline-earth cations; Whatman No. 1 paper $^{75}$. 


\section{CANDIN LITEANU AND SIMION GOCAN}

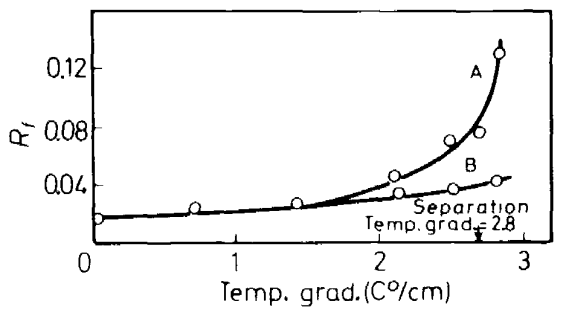

Figure 37. The plot of $R_{f}$ values versus temperature gradient for histidine $(A)$ and aspartic acid (B): Whatman No. 1 paper $^{7.3}$

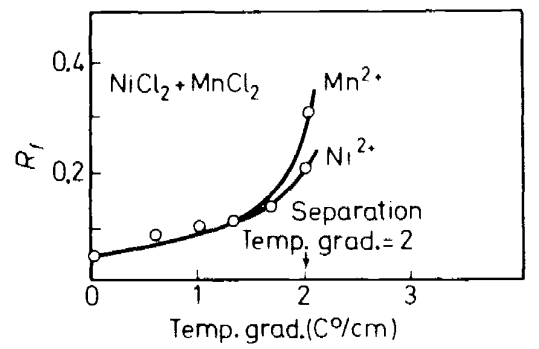

Figure 38. The plot of $R_{f}$ values versus temperature gradient for $\mathrm{Ni}^{2+}$ and $\mathrm{Mn}^{2+}$ : Whatman No. 4 paper"s.

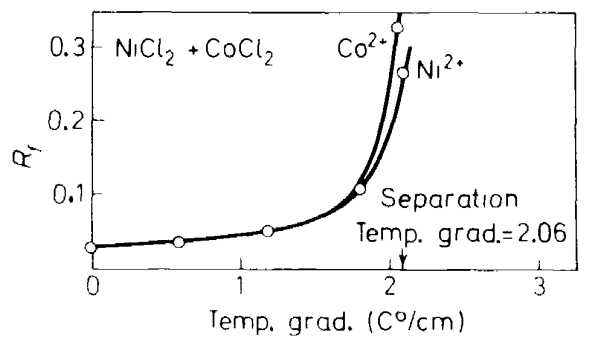

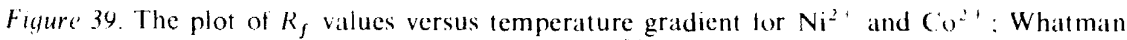
No. 3 paper $^{81}$.

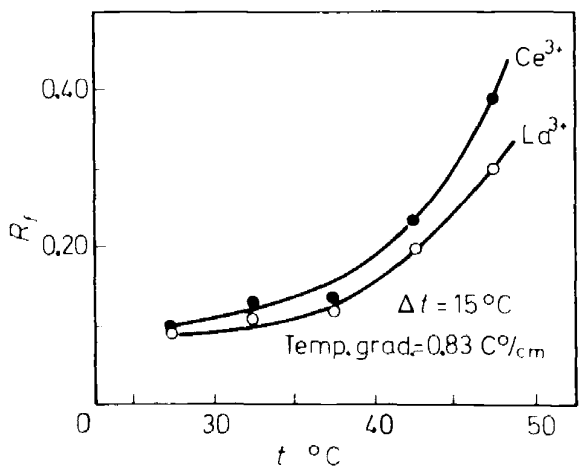

Figure 40. The plot of $R$, values versus the middle of the temperature interval for $\left(\mathrm{C}^{31}\right.$ and $\mathrm{La}^{3}$ at the temperature gradient $0.83 \mathrm{C} / \mathrm{cm}$ : Whatman No. 1 paper ${ }^{82}$. 
SOME ASPECTS OF SOLUTION CHROMATOGRAPHY WITH GRADIENTS

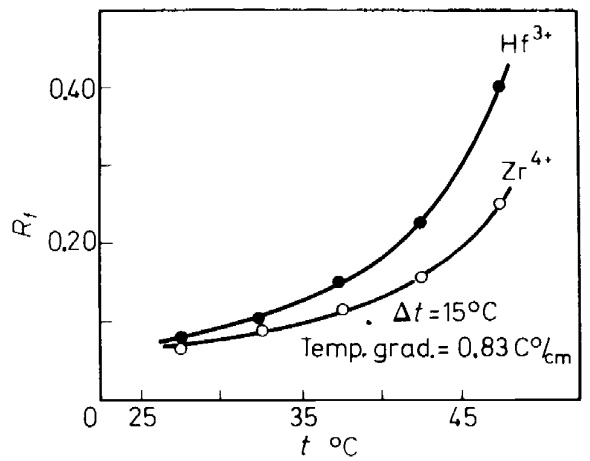

Figure 41. The plot of $R_{f}$ values versus the middle of the temperature interval for $\mathrm{Hf}^{3+}$ and $\mathrm{Zr}^{4+}$ at the temperature gradient $0.83^{\circ} \mathrm{C} / \mathrm{cm}$; Whatman No. 1 paper $^{82}$.

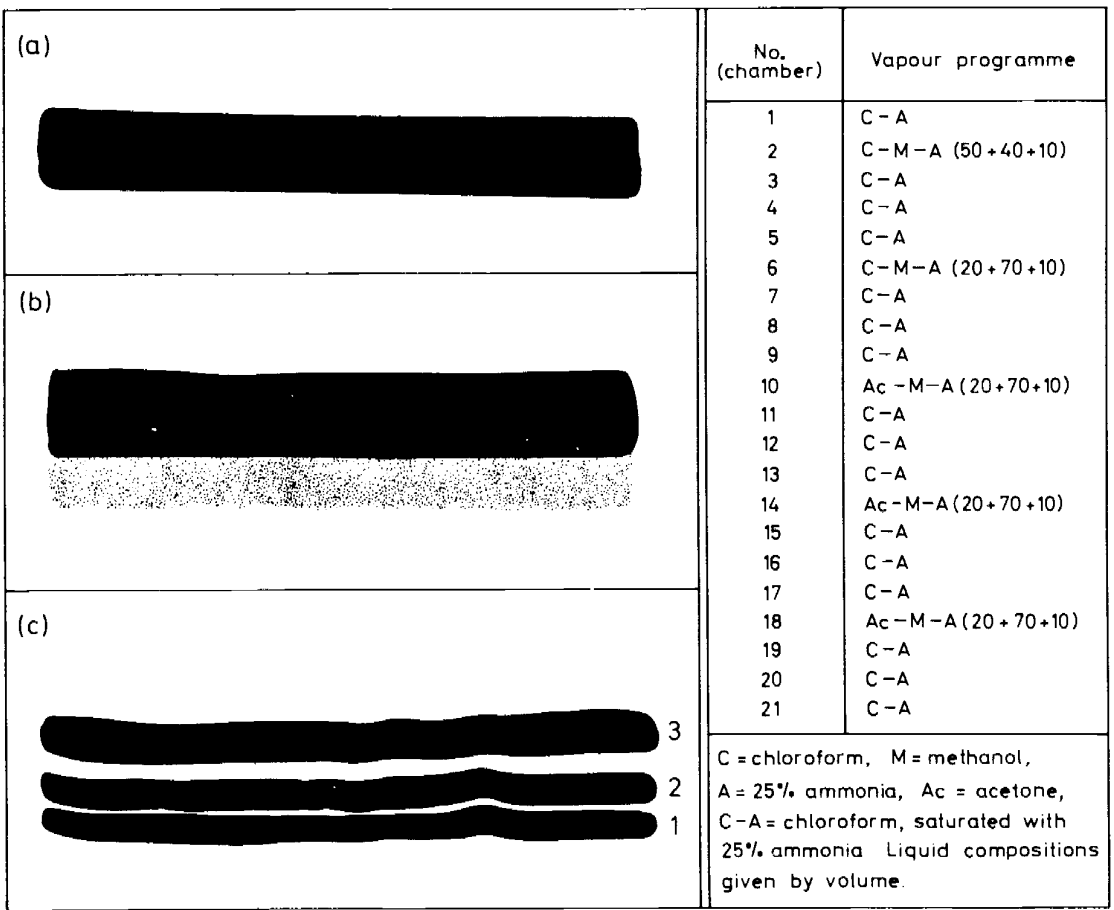

Figure 42. Separation of a mixture of sulphadiazine (1), sulphamerazine (2) and sulphamethazine (3) on silica gel layer ${ }^{44}$.

(a) Conventional development at $20.9^{\circ} \mathrm{C}$ in saturated chamber, eluent : chloroform-methanol$25 \%$ ammonia $(50 \cdot 40-10)$;

(b) As under (a), development repeated twice; (c) vapour programme chamber : eluent, chloroform-methanol-25\% ammonia (75-20-5). 


\section{CANDIN LITEANU AND SIMION GOCAN}

From the results in Figures 39 to 41 one can infer that the temperature gradient separation of particular substances is possible even in such cases when in isothermal chromatography $\left(20^{\circ} \mathrm{C}\right)$ practically identical $R_{f}$ values are obtained.

Stah $2^{25.2}$ showed that he, too, used a sort of temperature programming in thin-layer chromatography. In that case the temperature gradient was achieved by placing the chromatographic plates at room temperature in a chromatographic chamber at $-20 \mathrm{C}$ temperature.

Drapron and Guilbot ${ }^{38}$, who used a mobile phase evaporation gradient chamber for the separation of carbohydrates, succeeded in getting a better resolution of the domains, and higher reproducibility of the $R_{f}$ values and in improving the accuracy of extinction values measured by direct photometry.

Likewise, Turina and co-workers ${ }^{39}$ described an adaptor for the solvent evaporation at the top of the plate in order to lengthen the development time in thin-layer chromatography and improve resolution. Further Turina and co-workers ${ }^{83}$ used a heating device fitted on to the back of the chromatographic plate. The latter is heated during the chromatographic process, the solvent evaporates off the plate, thus increasing concentration in the middle of the area. and improving detection and resolution.
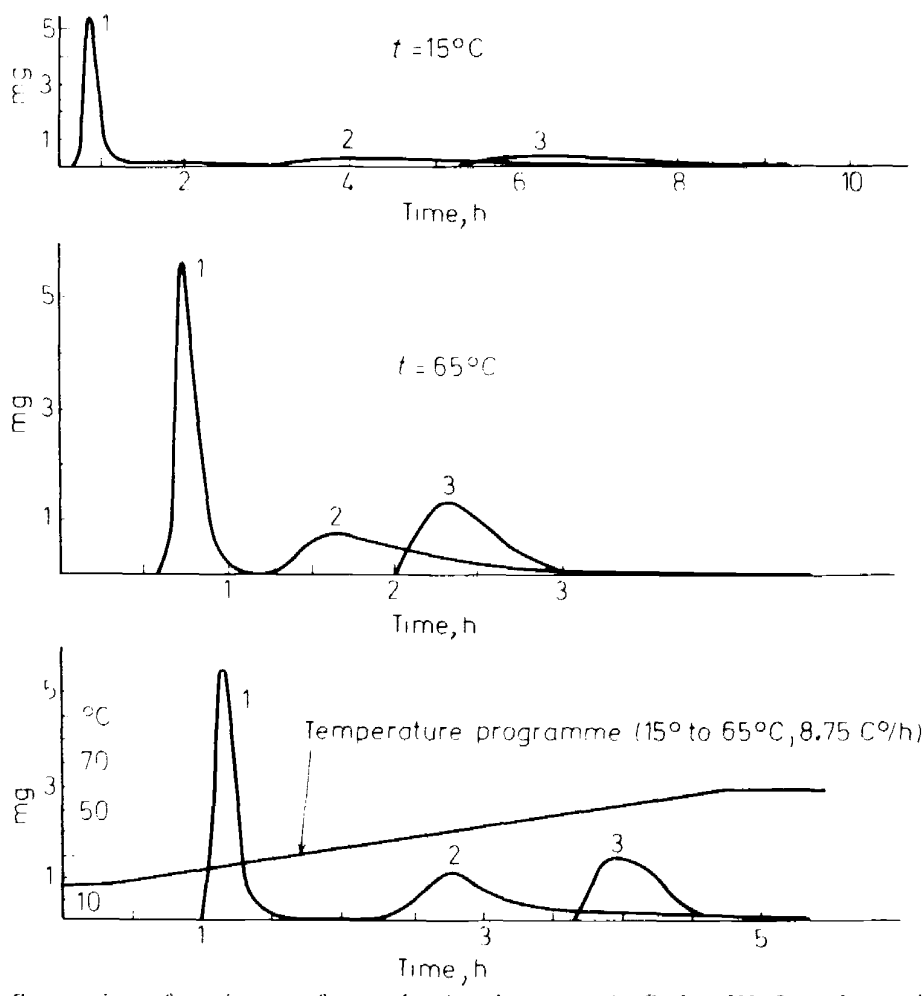

Figure 43. Separation of a mixture of $p$-methoxiazobenzene (1). Sudan III (2) and p-aminoazobenzene (3) on column (basic $\mathrm{Al}_{2} \mathrm{O}_{3}$ ) with temperature programme ${ }^{33}$. 
The programmed vapour-development technique in thin-layer chromatography has been used increasingly of late. This results in better resolution, as illustrated in Figure 42. Separation was performed ${ }^{44}$ by a chamber the shape of which was similar to that in Figure 28.

Hesse and Engelhard ${ }^{33}$ used programmed temperature to get better separations in a shorter time. The results of the process are comparable to the elution gradient technique (Figure 43).

In recent work we have used the temperature gradient to an ion-exchange closed column ${ }^{32}$. The result in terms of the plate height $H$ are given in Table 1.

Table 1. Plate height $H, \mathrm{~cm}$. Column length $30 \mathrm{~cm}$, inner diameter $1 \mathrm{~cm}$, cationite Dowex $50 \mathrm{X} 8(\mathrm{H}-\mathrm{R})$, eluent $\mathrm{HCl} 0.5 \mathrm{~N}, 5 \mathrm{ml} \mathrm{ZnCl}{ }_{2} 17 \mathrm{mg} / \mathrm{ml}, 2 \mathrm{ml} \mathrm{CoCl}{ }_{2} 19.5 \mathrm{mg} / \mathrm{ml}$.

\begin{tabular}{|c|c|c|c|c|c|}
\hline \multirow{2}{*}{ Ion } & \multicolumn{3}{|c|}{ Temperature, ${ }^{\circ} \mathrm{C}$} & \multicolumn{2}{|c|}{ Temp. grad., ${ }^{\circ} \mathrm{C} / \mathrm{cm}$} \\
\hline & 20 & 60 & 80 & $\frac{60-40}{30}=0.66$ & $\frac{80-60}{30}=0.66$ \\
\hline $\begin{array}{l}\mathrm{Zn}^{2+} \\
\mathrm{Co}^{2+}\end{array}$ & 2.40 & 2.18 & 2.06 & 1.92 & 1.75 \\
\hline $\mathrm{Co}^{2+}$ & 5.66 & 3.40 & 1.90 & 1.88 & 1.80 \\
\hline
\end{tabular}

An analysis of the tabulated values shows that the higher the temperature, the less the plate height. Also that the temperature gradient rather than the temperature itself affects the plate height to a greater extent.

\section{THE THEORY OF TEMPERATURE GRADIENT CHROMATOGRAPHY}

The theory of the stationary and mobile phase gradient chromatographic processes has been discussed in a number of articles ${ }^{1,2.23,48,49.84,85}$ and the aspects analysed in them will not be further considered. Here we shall dwell on a few problems of the theory of temperature gradient chromatography along open (paper and or thin-layer) columns and closed columns.

\section{OPEN CHROMATOGRAPHIC COLUMNS}

Chromatographic separation is governed by the dynamics of the column processes and efficiency (number of theoretical plates and the plate height $H$, respectively) and by the thermodynamical properties of the phases and components (separation selectivity). The degree of separation of two components is expressed by resolution $R_{\mathrm{S}}$ including the notions of both separation efliciency and separation selectivity.

In order to find the resolution in open-column temperature gradient chromatography ${ }^{86}$ we have started from the well-known relations defining resolution $^{87,88}$ in the form

$$
R_{\mathrm{S}}=\left(t_{2}-t_{1}\right) / 2\left(\sigma_{1}+\sigma_{2}\right)
$$




\section{CANDIN LITEANU AND SIMION GOCAN}

where $t_{2}$ and $t_{1}$ are the necessary times for the elution of components 2 and 1 , and $\sigma_{2}$ and $\sigma_{1}$ are the respective standard deviations. Alternatively

$$
R_{\mathrm{S}}=2 \Delta z /\left(X_{1}+X_{2}\right)
$$

where $X_{1}$ and $X_{2}$ are the widths of the two peaks at the bottom as determined by their intersecting the tangents through the points of inflection to the elution curves.

Consider two chromatographic zones (spots) on the paper band or chromatographic plate and their respective densitogram (Figure 44).

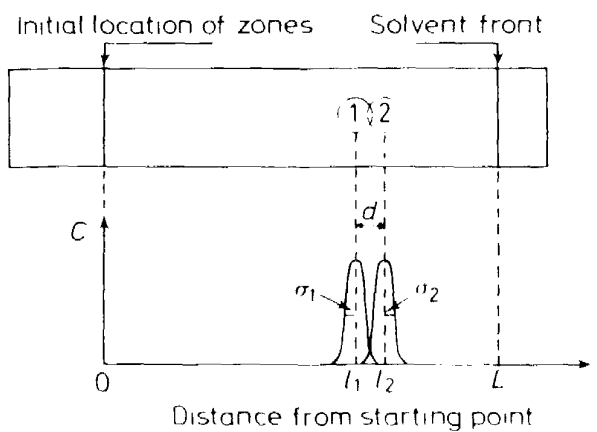

Figure 44. A chromatogram and its densitogram.

From Figure 44 one can see that the distance between the zone centres $d=l_{2}-l_{1}=R_{f 2} L-R_{f 1} L=\Delta R_{f} L=\Delta z$, as measured at the base of the peak between the tangents passing through the points of inflection to the concentration curve, is equal to $X_{1}=4 \sigma_{1}=4\left\{l_{1} H_{1}\right\}^{\frac{1}{2}}$ and $X_{2}=4 \sigma_{2}=$ $4\left\{l_{2} H_{2}\right\}^{\frac{1}{2}}$. where $R_{f}=l / L$ in both cases. By substituting into equation 12 one gets

$$
R_{\mathrm{S}}=\Delta R_{f} L^{\frac{1}{2}} / 2\left[\left\{R_{f 1} H_{1}\right\}^{\frac{1}{2}}+\left\{R_{f 2} H_{2}\right\}^{\frac{1}{2}}\right]
$$

but

$$
\left(R_{f}\right)_{\text {grad } \ell}=\left(R_{f}\right)_{\text {isoth. }}(V+\Delta V) / V
$$

and

$$
\left(\Delta R_{f}\right)_{\text {grad.tcmp }}=\left(\Delta R_{f}\right)_{\mathrm{isoth} .}(V+\Delta V) / V
$$

and considering that the chromatographic zones are quite near and of equal surface area for a temperature gradient chromatographic open column, the following relation is obtained

$$
\left(R_{\mathrm{S}}\right)_{\mathrm{grad} . t}=\frac{L^{\frac{1}{2}}}{4(H)_{\mathrm{grad} . t}^{\frac{1}{2}}}\left(\frac{\Delta R_{J}}{R_{J}^{\frac{1}{2}}}\right)_{\mathrm{isoth} .}\left(\frac{V+\Delta V}{V}\right)^{\frac{1}{2}}
$$

We shall now pass on to analysing how the temperature gradient helps to improve separation and raising resolution, respectively. The temperature 
gradient affects all the terms governing resolution except the length (the start-front distance) if expansion in terms of temperature is not considered.

\subsection{Effect of the temperature gradient upon the theoretical plate height $(H)$ grad.1}

The problem of the theoretical plate height $H$ in paper and thin-layer chromatography was tackled several times ${ }^{89-101}$. Generally, on each occasion it has been shown that the theoretical plate height $H$ includes three terms. The first is the contribution of turbulent diffusion, the second-of molecular diffusion, whereas the third is that of local inequilibrium. For instance, Stewart ${ }^{91}$ shows that in paper chromatography, the first term can be neglected, the second being significant only at high values assumed by $z_{f}^{2}=k t$, i.e. of the distance from the eluent level to the front $z_{f}$. The equation given ${ }^{99}$ for the plate height is the following

$$
H_{\mathrm{obs}}=A+\frac{B R_{f}}{\theta} \frac{z_{f}}{k}+\frac{C \theta k}{2 z_{f}} \ln \frac{R_{f} z_{f}}{z_{0}}
$$

where $R_{f}=A_{\mathrm{M}} /\left(A_{\mathrm{M}}+\alpha A_{\mathrm{s}}\right)$, viz. the relative velocity of the zone, $z_{0}=$ the distance from the eluent level to the start line, $\theta$ is the ratio of the solvent velocity to zone and front, while $A, B$ and $C$ are constants.

The temperature gradient acts upon the term expressing the local inequilibrium by lowering the $\theta$ value and $k$ (the constant in the equation of eluent flow), because of eluent evaporation along the column. In the temperature gradient technique; a far better equilibrium compared to isothermal chromatography is obtained, primarily because of the temperature rise with zone

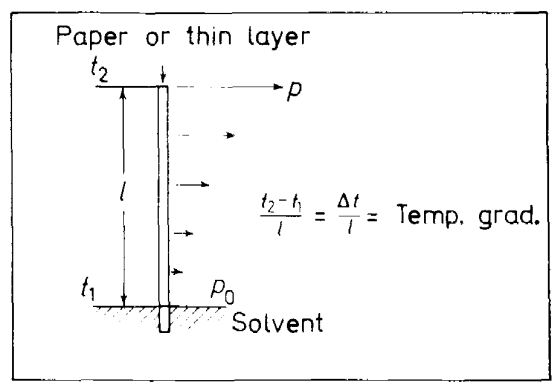

Figure 45. Diagrammatic representation of vapour tension along a chromatographic sheet ${ }^{86}$.

progressing, but also because of the velocity of the zone displacement steadily decreasing in consequence of the stronger evaporation rate with zone migration (Figure 45). Initially circular in shape by the end of the chromatographic process the zone assumes an elliptical shape whose short axis runs parallel to the eluent flow, as seen in the case of $\mathrm{Mn}^{2+}$ (Figure 46). This can be explained by the much higher evaporation rate in the front zone, hence smaller displacement velocities of both eluent and zone. 


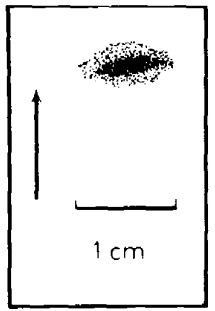

Figure 46. The shape of the spot for $\mathrm{Mn}^{2+}$ at the end of development: Whatman No. 3 paper ${ }^{86}$.

To sum up, in temperature gradient conditions the theoretical plate height is lower so a better resolution results.

\subsection{Changes of the $R_{f}$ and $\Delta R_{f}$ values induced by distribution coefficient variations}

We must admit that in temperature gradient conditions a variation of the distribution coefficient $\alpha$ occurs in consequence of two factors : temperature and eluent dehomogenization.

5.2.1. Changes of the distribution coefficient and of the $R$, values, respectively, uith temperature

As is already known, the relative velocity of the zone is given by relation

$$
R_{i}=1 /\left\{1+\left(A_{\mathrm{S}} / A_{\mathrm{M}}\right) \alpha_{\}}\right.
$$

where $\alpha=\exp \left(-\Delta G_{0} / R T\right)$ and $\Delta G_{0}$ is the standard distribution free energy; $R$ is the universal gas constant and $T$ is the absolute temperature.

For all substances for which $\Delta G_{0}<0$ the rising temperature induces a higher $R_{f}$ value. The temperature effect has been studied previously ${ }^{99-101}$.

In a number of investigated cases ${ }^{70,74.77}$, it was found that $\Delta R_{f}$ also became higher with rising temperature; hence, the $\Delta R_{f} / R_{f}^{\frac{1}{2}}$ ratio that may rise with temperature and resolution is a better indicator (formula 14).

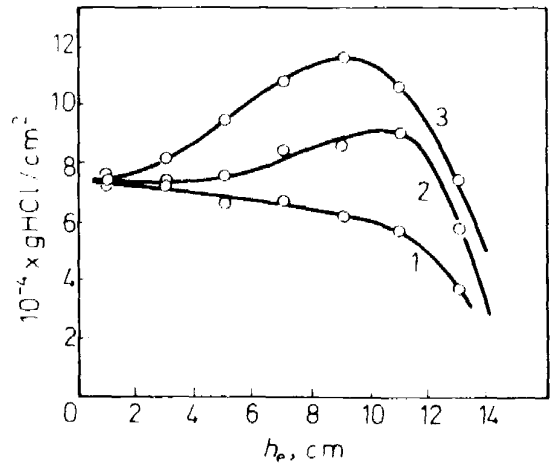

Figure 47. The distribution of hydrogen chloride on Whatman No. 4 paper. $1-$ isotherm $20^{\prime \prime} \mathrm{C}$; 2- temp. grad. $=0.5 \mathrm{C} / \mathrm{cm} ; 3$-temp. grad. $=1.0 \mathrm{C} / \mathrm{cm}^{76}$. 
5.2.2. Changes of the distribution coefficient with eluent dehomogenization

Dehomogenization of the mobile phase is well known in isothermal chromatography ${ }^{102-104}$. In temperature gradient conditions the eluent dehomogenization is more obvious due to further evaporation ${ }^{69.70 .76}$. The eluent being as a rule a mixture, it undergoes stronger dehomogenization than in isothermal conditions. To illustrate the statement, Figure 47 shows hydrogen chloride distribution on the chromatogram ${ }^{105}$. The temperature of the eluent in the tank was $20^{\circ} \mathrm{C}$ in all cases.

In general, higher hydrogen chloride concentrations on the chromatogram result in changed $\alpha$, and therefore also $R_{f}$ values, a fact that is well known in isothermal chromatography ${ }^{106.107}$.

Thus, we may say that dehomogenization caused by the temperature gradient due to steady evaporation yields, as the case may be, $\mathrm{pH}$, concentration, polarity or ion strength gradients.

As a conclusion, in temperature gradient chromatography, temperature effect combines with that of these gradients resulting from eluent dehomogenization to improve resolution.

\subsection{Higher resolution values due to the additional eluent volume $\Delta V$ passed through the column and evaporated}

In temperature gradient chromatography, an eluent volume $V+\Delta V$ is passed through the column. The amount of eluent leaving the column $\Delta V$ is a function of the evaporation rate, which in turn is governed by the magnitude of the temperature gradient, degree of saturation of the chamber and duration of the chromatographic process ${ }^{105}$. By $\Delta V$ only that part of the eluent volume is understood that evaporated along the column and was involved in the chromatographic distribution process ${ }^{108}$. As the duration of the process may be indefinitely long, any value can be obtained for $\Delta V$, and therefore a higher resolution, as seen from equation 14.

For the eluent displacement velocity in temperature gradient conditions, the following relation was established ${ }^{77}$

$$
v_{e}=\mathrm{d} h_{e} / \mathrm{d} \tau=A /(A+B \tau)^{2}
$$

( $A$ and $B$ are constants which depend on the experimental conditions). It is observed that the eluent displacement velocity steadily decreases, obviously because of its column evaporation, to become practically zero after not so long a time as seen in Table 2 . Under these conditions, $\Delta V \rightarrow \infty$ and as

Table 2. Height and eluent displacement velocity in terms of time ${ }^{105}$. Eluent : $n$-butanol saturated with normal hydrogen chloride, paper: Schleicher--Schüll $2040 \mathrm{~b} \mathrm{M}$, grad. $t .=2{ }^{\circ} \mathrm{C} / \mathrm{cm}, t_{i}=20^{\circ} \mathrm{C}$, $A=2.28 \mathrm{~min} / \mathrm{cm} . B=0.058 \mathrm{~min} / \mathrm{cm}$.

\begin{tabular}{rrlccl}
\hline $\begin{array}{c}\tau \\
\min \end{array}$ & $\begin{array}{c}h_{e} \\
\mathrm{~cm}\end{array}$ & $\begin{array}{c}v_{e} \\
\mathrm{~cm} / \mathrm{sec}\end{array}$ & $\begin{array}{c}\tau \\
\min \end{array}$ & $\begin{array}{c}h_{e} \\
\mathrm{~cm}\end{array}$ & $\begin{array}{l}v_{e} \\
\mathrm{~cm} / \mathrm{sec}\end{array}$ \\
\hline 1 & 0.43 & 0.95 & 1000 & 16.58 & 0.00066 \\
10 & 3.49 & 0.70 & 2000 & 16.90 & 0.00016 \\
100 & 12.37 & 0.05 & 2500 & 16.97 & 0.00010 \\
500 & 15.98 & 0.0026 & $\infty$ & $17.24^{*}$ & $0^{*}$ \\
\hline
\end{tabular}

* calculated 
$l=V / A_{\mathrm{M}}$ then $\Delta l=\Delta V / A_{\mathrm{M}} \rightarrow x$, that is chromatography proceeds as if the column were very long. In fact, in these circumstances, no matter how similar the displacement velocities, the mixture constituents will be separated.

\section{CHROMATOGRA PHIC CLOSED COLUMNS}

The effects of temperature on the shape of the elution curves, distribution constant and theoretical plate height in ion-exchange chromatographic separations was the object of much research ${ }^{109 \cdot 117}$.

Dybczynski ${ }^{115.116}$ evolved the following equation for the resolution of ion-exchanger filled column

$$
R_{\mathrm{S}}=(\beta-1) L^{\frac{1}{2}} / n(\beta+1) H^{\frac{1}{2}}
$$

where $\beta$ is the ratio between the distribution coefficient $K_{\mathrm{d}}$ of constituents two-to-one. $L$ is the length of the ion-exchanger filled column, $H$ is the average height of the plates $H_{1}$ and $H_{2}$ and $n$ a number which in ion-exchange chromatography is assumed to be three.

From equation 18 it is found that. for a given length of the column. resolution is a function of selectivity $\beta$, and of the plate height $H$. To see how temperature affects resolution through the two variables, their expressions must be written explicitly.

As is known from the theory of ion-exchange chromatography, the expression HETP has the following form ${ }^{104.118}$

$$
H=1.64 r+\frac{K_{\mathrm{d}}}{\left(K_{\mathrm{d}}+F_{\mathrm{l}}\right)^{2}} \quad \begin{gathered}
0.142 r^{2} r \\
D_{\mathrm{S}}
\end{gathered}+\frac{K_{\mathrm{d}}^{2} 0.266 r^{2} r}{\left(K_{\mathrm{d}}+F_{\mathrm{J}}\right)^{2} F_{11} D_{\mathrm{l}}(1+70 r v)}
$$

where $r$ denotes radius of resin grains, $r$ is the flowing velocity of the eluent. $K_{\mathrm{d}}$ is the coefficient of distribution at equilibrium. $D_{s}$ is the resin diffusion coefficient, $D_{\mathrm{l}}$ is the solution diffusion coefficient, $F_{\mathrm{I}}$ is the free section of the column. and $F_{11}=\left(1-F_{1}\right)$ is the section of the column filled with resin.

If longitudinal diffusion in the two phases is also taken into account. to equation 19 two more terms are added ${ }^{119}$.

This relation shows that the HETP value is made up of three terms: the first expresses the contribution of the particle size, the second that of diffusion into the resin grain and the third the contribution of diffusion into the liquid film surrounding the resin particle about $10^{-3} \mathrm{~cm}$ thick.

Temperature influences the HETP value through the distribution coefficient $K_{\mathrm{d}}$ and the diffusion coefficients $D_{\mathrm{l}}$ and $D_{\mathrm{S}}$. The relation expressing the dependence of the distribution cocificient $K_{4}$ on temperature assumes ${ }^{120}$ the form

$$
\ln K_{\mathrm{d}}=\ln \underset{{ }_{i \mathrm{~A}}}{\bar{\gamma}_{\mathrm{A}}}+\ln { }_{\bar{\gamma}_{\mathrm{BR}}}^{\bar{\gamma}_{\mathrm{BR}}}+\underset{R T}{P}\left(\bar{V}_{\mathrm{AR}}-\bar{V}_{\mathrm{BR}}\right)
$$

where $\gamma_{A}, \gamma_{B}$ are the activity coefficients of ions $\Lambda$ and $B . \gamma_{A R}, \bar{\gamma}_{B R}$ are the activity coefficients of the compounds AR, BR assuming infinite dilution of the resin. $P$ is the resin swelling pressure, $\bar{V}_{A R}, \bar{V}_{B R}$ are the partial molar volumes of the compounds $\mathrm{AR}$ and $\mathrm{BR} . R$ is the universal gas constant, and $T$. the temperature in Kelvin degrees. 
The diffusion coefficients $D_{\mathrm{L}}$ and $D_{\mathrm{S}}$ are temperature dependent according to the expression ${ }^{121}$

$$
D=D_{0} \exp (-E / R T)
$$

where $E$ is the activation energy (required by the molecule to pass from its initial position to a neighbouring one), and $D_{0}$ is a coefficient weakly dependent on temperature.

From the above it follows that the temperature effect upon the HETP value is highly complex, though a few qualitative considerations can be still made. As seen from equation 19, the diffusion coefficients being in the denominator and rising exponentially with temperature (equation 21), the conclusion is drawn that the HETP value must be affected rather strongly by temperature, that is to say, lowered. Since the distribution coefficient $K_{\mathrm{d}}$ may be higher, lower or remain constant with temperature, there exists the possibility that, in certain cases, the theoretical plate height will increase with temperature ${ }^{114}$.

In conclusion it can be stated that, as a rule, temperature rises affect positively the shape of the elution curves, hence the whole separation process, usually leading to better resolution.

The results ${ }^{32}$ on the elution curves at various temperatures for the $\mathrm{Zn}^{2+}$ and $\mathrm{Co}^{2+}$ ions are given in Figure 48 and 49. From them, one can see that at

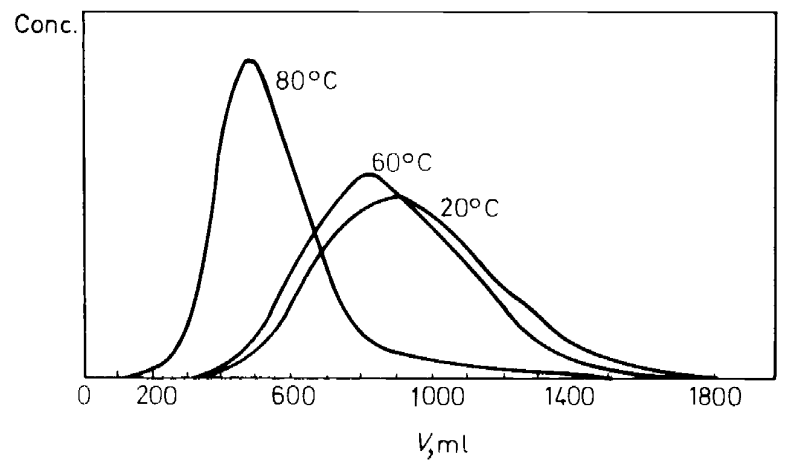

Figure 48. Intluence of temperature on clution curve for $\mathrm{Zn}^{2+}$ (cationite column) ${ }^{32}$.

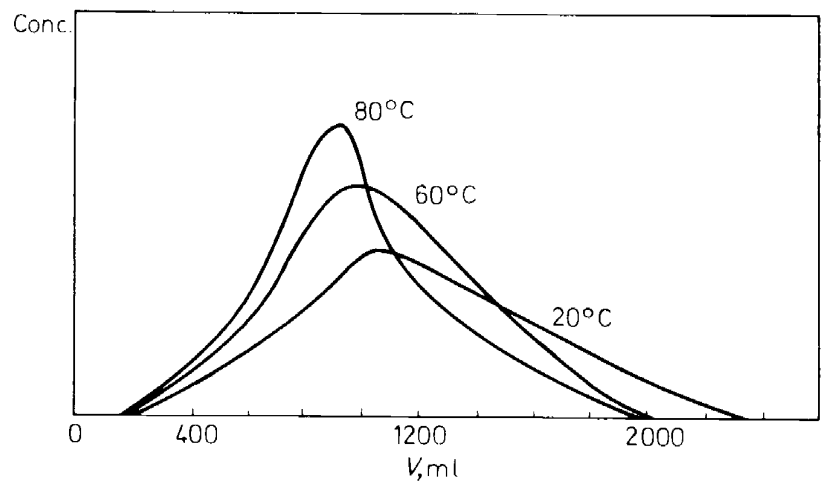

Figure 49. Influence of temperature on elution curve for $\mathrm{Co}^{2+}$ (cationite column) ${ }^{32}$. 
higher temperatures, smaller retention volumes are obtained because the elution curves are narrower (i.e. plate height becomes shorter as seen in Table 1) and resolution better.

The effect of the temperature gradient (along the column) on the HETP and the shape of the elution curves, respectively, will assume a more complex character, since the exchange process takes place at different temperatures, according to the zone shifting along the column. This will obviously result in a continuous variation of the ion-exchanging velocity along the column. The exchange velocity is a function of the diffusion processes in the solution film covering the grain. but especially of diffusion into the grain. Thus. at the front and bottom sides of the zone, the exchange velocity will differ. By appropriately selecting the temperature gradient, the shape of the elution curves. particularly asymmetric curves with long tails can be favourably affected.

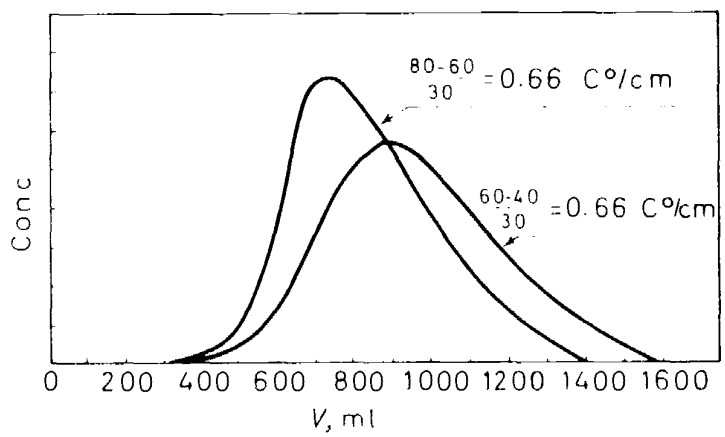

Figure 50. Influence of temperature gradient on elution curve for $\mathrm{Zn}^{2}$ (cationite column) ${ }^{32}$.

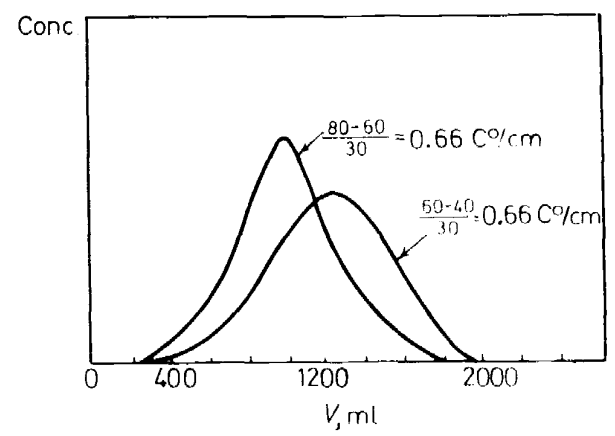

Figure 51 . Influence of temperature gradient on elution curve for $\left(\mathrm{Co}^{2+} \text { (cationite column }\right)^{32}$.

In work described in ref. 32 the chromatographic system was purposely selected so as to yield very long elution curves in isothermal conditions at $20 \mathrm{C}$, to illustrate better the temperature and temperature gradient effects. Figures 50 and $5 I$ show the elution curves for the $\mathrm{Zn}^{2+}$ and $\mathrm{Co}^{2+}$ ions. Upon analysing the elution curves in these figures, it is found that the higher the 
temperature or the temperature gradient, the smaller the retention and the total elution volumes and the shorter the analysis time.

An examination of the data in Table 1 discloses the stronger effect of the temperature gradient upon the plate height $H$ compared with that of temperature. In temperature gradient conditions, smaller $H$ values are obtained. This seems natural as an antiparallel temperature gradient was used on the column, the front side of the chromatographic zone being at a temperature below that at its bottom; consequently, the exchange process developed faster at the bottom leading to a shorter plate height $H$. The temperature gradient also entails a symmetrization of the elution curves.

This study is the first attempt to use the temperature gradient in closed column ion-exchange chromatography; further research will be conducted to apply this working technique to other chromatographic processes with a different mechanism (distribution and adsorption).

As inferred from what has been said, gradient chromatography has scored big successes. The possibilities to use different gradients for the optimization of the chromatographic separation processes are practically unlimited. Hence the growing interest of research workers in both theoretical and practical aspects involved in the use of gradients in the most varied chromatographic techniques.

\section{REFERENCES}

' L. R. Snyder, Chromatogr. Rev. 7, 1 (1965).

${ }^{2}$ E. Stahl. Z. Anal. Chem. 221, 3 (1966).

R. L. M. Synge, Disc. Faraday Soc. 7, 164 (1949).

${ }^{4}$ H. K. Mitchell, M. Gordon and F. A. Haskins, J. Biol. Chem. 180, 1071 (1949).

R. S. Alm, R. J. P. Williams and A. Tiselius, Acta Chem. Scand. 6, 826 (1952).

R. S. Alm. Acta Chem. Scand. 6, 1186 (1952).

R. J. P. Williams, Analyst, 77, 905 (1952).

${ }^{8}$ R. J. P. Williams, C. Hagdahl and A. Tiselius, Ark. Kcmi, 7, 4 (1954).

9 L. Hagdahl, R. J. P. Williams and A. Tiselius, Ark. Kemi, 4, 193 (1952).

${ }^{10}$ K. O. Donaldson, V. J. Tulane and L. M. Marshall, Analyt. Chem. 24, 185 (1952).

11 H. H. Strain, Analyt. Chem. 23, 25 (1951).

12 H. Busch, R. B. Hurlbert and V. R. Potter, J. Biol. Chem. 196, 717 (1952).

13 H. Busch and V. R. Potter, Cancer Res. 12, 660 (1952).

${ }^{14}$ H. Busch and V. R. Potter, Cancer Res. 13, 168 (1953).

15 C. Mader, Analyt. Chem. 26. 566 (1954).

16 M. Lederer. Nature, London, 172, 727 (1953).

17 J. A. Grande and J. Beaukencamp, Analyt. Chem. 28, 1495 (1956).

18 D. W. Bannister, C. S. Philips and J. P. Williams, Analyt. Chem. 26, 1451 (1954).

19 T. Wieland and H. Determann, Experientia, 18, 431 (1962).

20 S. M. Rybicka, Chem. \& Ind. (London), 302, 1947 (1962).

21 A. Niederwieser and C. G. Honegger, Helv. Chim. Acta, 48, 893 (1965).

22 A. Niederwieser, J. Chromatogr. 21, 326(1966).

23 A. Niederwieser and C. G. Honegger, Chap. 4 in Gradient Techniques in Thin-layer Chromatography by J. C. Giddings and R. A. Keller (Eds), Vol. II, p 123. Arnold: London: Dekker : New York (1966).

24 E. Stahl, German Pat. No. 1175912 (1964) (Appl. 1961);

25 E. Stahl, Angew'. Chem. Internat. Ed. Engl. 3, 784 (1964).

26 E. Stahl and H. Vollmann, Talanta, 12, 525 (1965).

27 J. A. Berger, G. Meyniel, J. Petit and P. Blanquet. Bull. Soc. Chim. France, 2662 (1963):

- C.R. Acad. Sci., Paris. 257, 1534 (1963).

28 D. C. Abott and J. Thomson, Chem. \& Ind. (London), 310 (1965).

${ }^{29}$ R. G. Strickland, Analyt. Biochem. 10, 108 (1965). 


\section{CANDIN LITEANU AND SIMION GOCAN}

${ }^{30}$ C G. Honegger. Helv. Chim. Acta. 47. 2384 (1964).

$3 !$ C. Liteanu and S. Gocan. Stud. Unir. Babes-Bolyai, Chem. 6, 99 (1961).

32 C. Liteanu. S. Gocan. T. Hodişan. H. Naşcu and C. Măruţoiu, Rever. Roumaine Chim. 17. 497 (1972).

${ }^{33}$ G. Hesse and H. Engelhardt. J. Chromatogr. 21, 228 (1966).

34 R. J. Maggs and T. E. Young, Symposium of Gas Chromatography, 1968, Copenhagen, p 217. Edited by C. L. A. Herbourn. London (1969).

35 R. J. Maggs. J. Chromatogr. Sci. 7.145 (1969)

36. R. P. W. Scott and J. G. Lawrence, J. Chromatogr. Sci. 7, 65 (1969).

3- E. Stahl. Lıb. Pirlitice. 13. 496(1964).

38 R. Drapron and A. Guilbot, Chromatographie et Méthodes des Séparations Immédiates, Vol. 11. p 27. G. Parissakis Ed.. Publication de JUnion des (himustes Hellenes: Athens (1966).

39 S. Turina, V. Marjanovic, S. Krajovän and Z. Solic, J. Chromatogr. 40, 471 (1968).

40 R. A. De Zeeuw. J. Chromatogr. 32. 43 (1968).

4 R. A. De Zeeuw. Analyt. Chem. 40,915 (1968).

4? R A De Zeeuw. Pham. Wiekblat. 104. 1173 (1969).

+3 R. A. De Zeeuw. Analit. Chem. 40.2134(1968).

+4 R. A. De Zeeuw and J. Wijsbeek. Analyt. Che'm. 42.90 (1970).

t5 F. Geiss. S. Sandroni and H. Schlitt. J. Chromatogr. 44, 290 (1969).

th A. Niederwieser, Chromatographia, 2. 23 (1969).

$4^{-}$A. Niederwieser. Chromatographia. 2. 362 (1969).

t8 P. Lebretun. Bull. Soc: Chim. France. $2188(1960)$

${ }^{44}$ K. Dooner. Chemiker Ztg. 87. 871 (1963).

50 A. Cherkin. F. F. Martinez and M. S. Dunn. J. Amer. Chem. Soc. 75. 1244 (1953).

$\therefore$ H. R. Warner and W. E. M. Lands. J. Lipid Re's. 1. $248(1960)$.

52 R. M. Bock and N. S. Ling. Analyt. Che'm. 26. $1543(1954)$.

5.3 B. Drake. Ark. Kemi. 8. 1 (1955).

54 A. Bendich. H. B. Pal. G. C. Korngold. H. S. Rosenkranz and J. R. Fresco, J. Amer. Chem. Soc. $80.3949(1958)$

$\therefore$ N. E. Shelley. Analyt Chem. 33. $271(1961)$.

it G. L. Miller. Analyt. Biochem. 2. $133(1960)$

5. V. Anselmo. U.S. At. En. Comm. COO-1618-1. Avoil. Dept. CFST. 11 pp. (1967); From Nucl. Sci. Abstr. 21(21). 38958 (1967).

sa W. C. Kenyon. J. F. McCarley. E. G. Boucher. A. F. Robinson and A. K. Wiebe. Analyt. Che'm. 27. 1888 (1955).

:4 A. E. Kellie and A. P. Wade, Binchem. J. 66. 196 (1957).

(A) L. R. Snyder and H. D. Warren. J. Chromatogr. 15, 344 (1964).

.1 I. I. Wren. J. Chromatogr. 12. 32 (1963).

6.2 I. A. Peterson and H. A. Sober. Analyt. Chem. 31. 857 (1959)

6.3 E. A. Peterson and J. Rowland. J. Chromatogr. 5, 330 (1961).

f. 4 (. A. Baker and R. J. P. Williams, J. Chem. Soc. 2952 (1956)

45 (. Liteanu and S. Gocan. Bull. Soc. Chim. France, 1416 (1969).

"D. C. Abbot and J. Thomson. Analyst. 89. 613 (1964).

$\therefore$ K. A. Kraus and G. E. Moore. J. Amer. Chem. Soc. 75, 1460 (1955).

68 W. E. Nevrik, J. Phys. Chem. 59.690(1955).

${ }^{9}$ C. Liteanu and S. Gocan. Stud. Unit. Bahes-Bolyai, Chem. 7, 99 (1962).

" C. Liteanu and S. Gocan. Re'. Chim. Acud. RPR. 7. 1041 (1962).

' C. Liteanu and S. Gocan. Ret. Roumaine Chim. 9, 651 (1964).

*2 S. Gocan and C. Liteanu. Rer. Roumaine Chim. 9. 715 11964).

- C. Liteanu and S. Gocan, Rev. Roumaine Chim. 10, 1051 (1965).

${ }^{4}$ C. Litcanu and S. Gocan, Stud. Univ. Bahes Bolyai, Chem. 11. 71 (1966).

"s C. Liteanu. S. Gocan and Maria Onişor, Stud. Univ. Babes Bolyai. Chem. 11, 79 (1966).

if C. Liteanu and S. Gocan. Bull. Soc. Chim. France. 3836 (1967).

S. Cocan and C. Liteanu. Bull. Soc. Chim. France. 1409 (1967).

-4 C. Liteanu and S. Gocan, Stud. Univ. Bahes Bolyai. Chem. 13, 135 (1968).

${ }^{-9}$ C. Liteanu and S. Gocan. Talanta, 17, 1115 (1970).

80 C. Liteanu, F. Mărgineanu and D. Macarovici, Rev. Roumaine Chim. 12, 503 (1967).

1 C. Liteanu. S. Gocan and T. Hodişan, Rev. Roumaine Chim. 15, 1751 (1970).

s 2 . Gocan. T. Hodişan. Margareta Liteanu and C. Liteanu. Stud. Univ, Babes Bolyai, Chem. 16, 37 (1971). 


\section{SOME ASPECTS OF SOLUTION CHROMATOGRAPHY WITH GRADIENTS}

${ }^{83}$ S. Turina, Z. Soljic and V. Marjanovic, J. Chromatogr. 39, 81 (1969).

${ }^{84}$ L. R. Snyder and D. L. Saunders, J. Chromatogr. 44, 1 (1969).

85 L. R. Snyder and D. L. Saunders, J. Chromatogr. Sci. 7, 195 (1969).

86 S. Gocan and C. Liteanu, Rev. Roumaine Chim. 17, 661 (1972).

87 T. E. Ellerington, Gas Chromatography, p 198. D. H. Desty (ed.). Butterworths: London (1958).

88 W. L. Jones and R. Kieselbach, Analyt. Chem. 30, 1590 (1958).

${ }^{89}$ K. L. Mallik and J. C. Giddings, Analyt. Chem. 34, 760 (1962).

90 C. L. De Ligny and D. Bax, Z. Anal. Chem. 205, 22 (1964).

91 G. H. Stewart, Advances in Chromatography, Vol. I, p 107. J. C. Giddings and R. A. Keller (eds.). Arnold: London (1965).

92 G. H. Stewart, Separ. Sci. 1, 135 (1966).

93 C. L. De Ligny and W. Van De Meent, J. Chromatogr. 53, 469 (1970).

${ }^{94}$ C. L. De Ligny and A. G. Remijnse, J. Chromatogr. 33, 242 (1968).

95 C. L. De Ligny and A. G. Remijnse, J. Chromatogr. 35, 257 (1968).

96 C. L. De Ligny, J. Chromatogr. 49, 393 (1970).

97 C. L. De Ligny and A. G. Remijnse, Rec. Trav. Chim. Pays-Bas, 86, 410, 421 (1967).

98 G. H. Stewart, Separ. Sci. 1, 747 (1966).

99 C. S. Knight, Nature, London, 200, 1314 (1963).

${ }^{100}$ G. Parissakis and D. Vrandi-Piscou, Journées Hellénes de Séparation Immédiate et de Chromatographie; III-émes JHSIC, p 61 (1965).

101 F. Geiss and H. Schlott, J. Chromatogr. 33, 208 (1968).

102 A. Grün, Chimia, 11, 173 (1951).

103 L. Horner, W. Emerich and A. Kischner, Z. Elektrochem. 56, 987 (1952).

104 J. Dixmier, P. Dupuis and M. Hortz, Chim. Anal. 38, 129 (1956).

105 C. Liteanu and S. Gocan, Bull. Soc. Chim. France, 4527 (1970).

106 T. Născuțiu, Rev. Roumaine Chim. 9, 4 (1964); 10, 10 (1964); 12, 839 (1967).

107 G. de Carvalho, Anal. Chim. Acta, 16, 555 (1957).

${ }^{108}$ S. Gocan, Cecilia Coste-Ciupală, T. Hodişan and C. Liteanu, Rev. Roumaine Chim. 16, 1069 (1971).

109 P. B. Hamilton, D. C. Bogue and R. A. Anderson, Analyt. Chem. 32. 1782 (1960).

110 Ulla-Britt Larson, I. N. Norstedt and O. Samuelson, J. Chromatogr. 22, 102 (1966).

111 K. A. Kraus and R. J. Raridon, J. Amer. Chem. Soc. 82. 3271 (1960).

112 R. Dybczynski, Roczn. Chem. 37, 1411 (1963).

113 J. Minczewski and R. Dybczynski, Chem. Analit. (Warsawa), 10, 1113 (1965).

114 G. Brunisholtz and R. Roulet, Chimia, 21, 188 (1967).

115 R. Dyczynski, J. Chromatogr. 14, 79 (1964).

116 R. Dybcz.ynski, J. Chromatogr. 31, 155 (1967).

117 R. Dybczynski and Ludmila Wodkiewicz, J. Inorg. Nucl. Chem. 31, 1495 (1968).

118 E. Glueckauf, Ion Exchange and Its Applications, p 34. Society of Chemical Industry: London (1955).

119 R. Dybczynski, J. Chromatogr. 50, 487 (1970).

120 G. E. Myers and G. E. Boyd, J. Phys. Chem. 60, 521 (1956).

121 J. Giddings, Dynamics of Chromatography, Part 1: Principles and Theory, $\mathrm{p} 232$. Vol. I of 'Chromatography Science Series', Marcel Dekker: New York (1965). 